\title{
Definição de faixas de conforto e desconforto térmico para espaços abertos em Curitiba, PR, com o índice UTCI
}

\author{
Definition of thermal comfort and discomfort ranges for \\ open spaces in Curitiba, PR, with the UCTI index
}

\section{Francine Aidie Rossi \\ Eduardo Leite Krüger \\ Peter Bröde}

Francine Aidie Rossi Departamento de Expressão Gráfica Universidade Federal do Paraná Avenida Coronel Francisco Heráclito dos Santos, 210, Jardim das Américas Curitiba - PR - Brasil CEP 81531-970

Tel. : (41) 3361-3461

E-mail: francinea.rossi@hotmail.com

Eduardo Leite Krüger Programa de Pós-Graduação em Tecnologia Universidade Tecnológica Federal do

Av. Sete de Setembro, 3165 Rebouças Curitiba - PR - Brasil CEP 80230-901

Tel.: (41) 3310-4725 Ramal: 4725 E-mail: ekruger@utfpr.edu.br

Peter Bröde Leibniz-Institut für Arbeitsforschung an der Tecnischen Universität Dortmund Ardeystrasse 67 D-44139 Dortmund Deutschland Tel.: +49 (0) 231-10840 E-mail: broede@ifado.de

Recebido em 28/09/11

Aceito em 06/03/12

\section{Resumo}

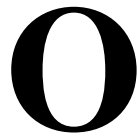

planejamento e a readequação urbana de espaços abertos são capazes de promover a melhoria das condições térmicas externas, influenciando positivamente o uso de espaços abertos. Neste contexto, foi realizada uma pesquisa para analisar o conforto térmico de transeuntes em ruas de pedestre em Curitiba, Paraná. Este artigo tem como objetivo definir faixas de conforto e desconforto térmico para Curitiba, propondo tais faixas para o índice UTCI (Universal Thermal Climate Index) para as condições climáticas locais a partir de um percentual aceitável de pessoas insatisfeitas com o ambiente térmico no espaço aberto. Para tal, foram analisados dados climáticos e dados pessoais obtidos por meio de monitoramento de campo em ruas de pedestre. Conclui-se que o índice UTCI teve boa capacidade preditiva para a amostra analisada e que as diferenças entre os subgrupos gênero, idade e índice de massa corpórea eram pequenas. A partir das análises das respostas reais de sensação térmica sugerem-se as seguintes faixas de conforto/desconforto térmico: desconforto para o frio, $\mathrm{Ta} \leq 15^{\circ} \mathrm{C}$; conforto, $15^{\circ} \mathrm{C}<\mathrm{Ta}<24^{\circ} \mathrm{Ce}$ desconforto para o calor, Ta $\geq 24^{\circ} \mathrm{C}$. A análise do índice UTCI mostrou a necessidade de calibração das faixas, sendo sugeridas as seguintes faixas para situações climáticas similares às de Curitiba: desconforto para o frio, $\mathrm{Ta} \leq 15^{\circ} \mathrm{C}$; conforto, $15^{\circ} \mathrm{C}<\mathrm{Ta}<27^{\circ} \mathrm{C}$ e desconforto para o calor, $\mathrm{Ta} \geq 27^{\circ} \mathrm{C}$.

Palavras-chave: Conforto térmico em espaços abertos. Índices de conforto. UTCI.

\section{Abstract}

Under the assumption that urban planning and alterations in open spaces are able to promote the improvement of outdoor thermal conditions and thus positively influence the use of open spaces, a survey was conducted to analyse the thermal comfort of passers-by in pedestrian streets in Curitiba, Paraná. This article aims to define ranges of thermal comfort and thermal discomfort for Curitiba, using the UTCI (Universal Thermal Climate Index) index for local climatic conditions from acceptable percentages of dissatisfied people in open spaces. An analysis was made of a sample of climatic and personal data gathered from field monitoring campaigns in pedestrian streets. The results indicate that the UTCI thermal index was a good predictor for the existing sample and that differences regarding gender, age and body mass were negligible. From the thermal sensation analyses, the following ranges are suggested for thermal comfort and discomfort: discomfort due to cold, Ta $\leq 15^{\circ} \mathrm{C}$; comfort, $15^{\circ} \mathrm{C}<\mathrm{Ta}<24^{\circ} \mathrm{C}$; and discomfort due to heat, $T a \geq 24^{\circ} \mathrm{C}$. The UTCI analysis showed the need for calibration for climatic conditions similar to those of Curitiba: discomfort due to cold, $\mathrm{Ta} \leq 15^{\circ} \mathrm{C}$; comfort, $15^{\circ} \mathrm{C}<\mathrm{Ta}<27^{\circ} \mathrm{C}$ and discomfort due to heat, $\mathrm{Ta} \geq 27^{\circ} \mathrm{C}$.

Keywords: Thermal comfort in open spaces. Comfort indices. UTCI. 


\section{Introdução}

Nos últimos anos tem crescido o interesse em analisar o conforto térmico em espaços abertos visando ao planejamento urbano. Sabe-se que, independentemente de seu uso, a avaliação e a compreensão do conforto térmico nesses espaços podem auxiliar a melhoria da qualidade urbana, influenciando positivamente o uso e o comportamento das pessoas. Segundo Nikolopoulou (2004), áreas bem planejadas atraem maior número de pessoas, turismo, comércio, trabalhadores e residentes, sendo atrativas economicamente. Além disso, torna-se possível melhorar o clima local, encorajando a partir da boa prática o planejamento de outras áreas. Dessa forma, as condições microclimáticas têm sido consideradas essenciais para a atratividade do espaço aberto e, indiretamente, para seu uso (NIKOLOPOULOU; LYKOUDIS, 2006).

Entre as pesquisas de conforto térmico em espaços abertos destacam-se aquelas que analisam os fatores psicológicos e comportamentais do uso do espaço em função do conforto térmico (NIKOLOPOULOU; BAKER; STEEMERS, 2001; NIKOLOPOULOU; STEEMERS, 2003; THORSSON; LINDQVIST; LINDQVIST, 2004; NIKOLOPOULOU; LYKOUDIS, 2006; KNEZ; THORSSON, 2006; ELIASSON et al., 2007; KNEZ et al., 2009) e aquelas com o objetivo de analisar a influência do desenho urbano no conforto térmico utilizando índices de conforto baseados no balanço térmico do corpo humano. Nessa linha, por exemplo, há pesquisas que analisam as relações entre cânions urbanos e conforto térmico (ALI-TOUDERT; MAYER, 2006; JOHANSSON, 2006; JOHANSSON; EMMANUEL, 2006; KRÜGER; MINELLA; RASIA, 2011) e entre vegetação e conforto térmico (SHASHUA-BAR; HOFFMAN, 2000; PICOT, 2004). Além de estudos que apresentam soluções para readequação do espaço público tendo em vista a melhoria do conforto térmico (GIVONI, 1998; CHRISOMALLIDOU; CHRISOMALLIDIS; THEODOSIOU， 2004; KATZSCHNER, 2005; KATZSCHNER; MÜLDER, 2005; PANOGOPOULOS, 2008).

De modo geral, as pesquisas sobre conforto térmico em espaços abertos utilizam índices de conforto térmico baseados em modelos de balanço térmico do corpo humano, que foram desenvolvidos para o ambiente interno. Entretanto, algumas pesquisas questionam o uso desses índices para a avaliação do ambiente externo (HÖPPE, 2002; SPAGNOLO; DE DEAR 2003; NIKOLOPOULOU; STEEMERS, 2003).
No Brasil, nos últimos 20 anos, de acordo com estudos publicados nos anais do Encontro Brasileiro de Conforto Térmico no Ambiente Construído (Encac), as pesquisas sobre clima urbano podem ser divididas em dois grandes temas:

(a) as pesquisas sobre a relação entre o microclima e a morfologia urbana; e

(b) as pesquisas sobre microclima e conforto térmico em espaços abertos.

A maior parte dos estudos concentra-se nas regiões Sudeste e Nordeste do país. As pesquisas sobre conforto térmico em espaços abertos que analisam a aplicação de índices existentes para a avaliação do conforto térmico utilizam principalmente os índices PMV, PET e SET*.

Souza et al. (2010) analisaram uma fração urbana residencial da cidade de Bauru, SP, com o objetivo de avaliar o papel do fator de visão do céu na intensidade de ilhas de calor e gerar informações que contribuam com o planejamento urbano. Os autores testaram o modelo genérico de Oke e fizeram um ajuste nesse modelo, com base nas características locais. Os resultados sugerem a necessidade de calibração do modelo para os parâmetros urbanos locais.

Pereira e Assis (2010) analisaram quatro índices de conforto adaptativo, definidos por estudos brasileiros para ambientes internos realizados em Florianópolis, SC, Fortaleza, CE, e Belo Horizonte, MG. Os autores utilizaram os dados de temperatura média mensal extraídos das Normais Climatológicas para o cálculo dos índices $\mathrm{e}$ compararam com os resultados obtidos com os estudos dos três estudos de referência. Concluiu-se que índices adaptativos podem ser aplicados para a determinação do conforto térmico unicamente a partir da temperatura do ar externa, sendo necessária a utilização de outras variáveis apenas em situações mais complexas.

Monteiro e Alucci (2010) apresentam uma análise comparativa entre pesquisas laboratoriais e de campo em conforto térmico em espaços abertos urbanos com base em resultados obtidos para a cidade de São Paulo, SP. A partir de variáveis climáticas, pessoais e subjetivas obtidas em levantamentos de campo, foram calibrados vários índices para dados coletados durante pesquisa laboratorial e de campo. Conclui-se que as calibrações realizadas com base na pesquisa laboratorial, mais controlável, obtiveram melhores resultados preditivos que as calibrações feitas a partir das pesquisas de campo. 
Bröde, Krüger e Rossi (2011) utilizaram o índice UTCI para analisar o impacto das variáveis climáticas, temperatura e umidade do ar, velocidade do vento e radiação solar, na escolha de isolamento térmico de pedestres em Curitiba. Os resultados mostram que, relativamente aos resultados encontrados para homens, as mulheres escolhem menos isolamento térmico em condições quentes e essa escolha depende da temperatura do ar, da radiação solar e da estação do ano.

O UTCI (Universal Thermal Climate Index) foi desenvolvido pela ISB Commission 6 da Sociedade Internacional de Biometeorologia (ISB International Society of Biometeorology) com o objetivo de avaliar as condições térmicas de ambientes externos por meio da resposta fisiológica do corpo humano, sendo definido como termo fisiologicamente válido, aplicável a todos os tipos de clima e independente das características pessoais dos indivíduos. (INTERNATIONAL..., 2001, 2003).

O Universal Thermal Climate Index (UTCI) foi elaborado com base no modelo termorregulatório multinodal desenvolvido por Fiala, Lomas e Stohrer. (1999, 2001, 2003, 2007) e Fiala et al. (2011) que consideram:

(a) o comportamento adaptativo em relação ao isolamento térmico a partir de estudos de campo desenvolvidos na Europa;

(b) a distribuição da roupa em diferentes partes do corpo; e

(c) a redução da resistência térmica e evaporativa da roupa causada pelo vento e pelo movimento da pessoa andando a $4 \mathrm{~km} / \mathrm{h}$ em superfície plana.
O UTCI segue o conceito da temperatura equivalente $\mathrm{e}$ apresenta para $\mathrm{o}$ ambiente de referência as seguintes definições:

(a) $50 \%$ de umidade relativa (com pressão de vapor não excedendo $20 \mathrm{hPa}$ );

(b) (a) temperatura do ar (Ta) igual a temperatura radiante média (Trm); e

(c) (a) velocidade do vento de $0,5 \mathrm{~m} / \mathrm{s}$, medida a $10 \mathrm{~m}$ de altura.

A igualdade das condições fisiológicas é baseada na equivalência da resposta fisiológica dinâmica prevista pelo modelo para o ambiente real e para o ambiente de referência. Como essa resposta dinâmica é multidimensional (temperatura corporal, taxa de sudorese, temperatura da pele, etc. em diferentes tempos de exposição), um índice unidimensional foi estimado através da Análise dos Componentes Principais. Assim, a temperatura UTCI equivalente para dada combinação das variáveis climáticas (vento, radiação, umidade e temperatura do ar) é definida como a temperatura do ar do ambiente de referência, que produz o mesmo valor de estresse térmico.

O UTCI abrange as seguintes faixas climáticas: $50{ }^{\circ} \mathrm{C} \leq \mathrm{Ta} \leq 50{ }^{\circ} \mathrm{C},-30{ }^{\circ} \mathrm{C} \leq \mathrm{Trm}-\mathrm{Ta} \leq 70{ }^{\circ} \mathrm{C}$, velocidade de vento entre 0,5 e $30,3 \mathrm{~m} / \mathrm{s}$ e umidade relativa de $5 \%$ a $100 \%$ (pressão de vapor máxima $5 \mathrm{kPa}$ ). Apresenta as faixas de estresse térmico contidas na Tabela 1.

Por considerar que o índice UTCI foi desenvolvido tendo como base estudos de campo europeus, este estudo tem o objetivo de apresentar faixas de conforto/desconforto para o índice UTCI a partir de dados de sensação térmica real em monitoramentos térmicos urbanos, sob condições subtropicais.

Tabela 1 - Faixas de estresse térmico do UTCI

\begin{tabular}{c|l}
\hline Faixas de UTCI & \multicolumn{1}{c}{ Categorias de estresse } \\
\hline$>46{ }^{\circ} \mathrm{C}$ & extremo estresse para o calor \\
$38{ }^{\circ} \mathrm{C} \mathrm{a} 46{ }^{\circ} \mathrm{C}$ & muito forte estresse para o calor \\
$32^{\circ} \mathrm{C} \mathrm{a} 38^{\circ} \mathrm{C}$ & forte estresse para o calor \\
$26{ }^{\circ} \mathrm{C} \mathrm{a} 32^{\circ} \mathrm{C}$ & moderado estresse para o calor \\
$18{ }^{\circ} \mathrm{C} \mathrm{a} 26{ }^{\circ} \mathrm{C}$ & conforto térmico \\
$9{ }^{\circ} \mathrm{C} \mathrm{a} 18^{\circ} \mathrm{C}$ & sem estresse térmico \\
$0{ }^{\circ} \mathrm{C} \mathrm{a} 9{ }^{\circ} \mathrm{C}$ & pouco estresse para o frio \\
$0{ }^{\circ} \mathrm{C} \mathrm{a}-13{ }^{\circ} \mathrm{C}$ & moderado estresse para o frio \\
$-13{ }^{\circ} \mathrm{C} \mathrm{a}-27^{\circ} \mathrm{C}$ & forte estresse para o frio \\
$-27{ }^{\circ} \mathrm{C} \mathrm{a}-40{ }^{\circ} \mathrm{C}$ & muito forte estresse para o frio \\
$<-40{ }^{\circ} \mathrm{C}$ & extremo estresse para o frio \\
\hline
\end{tabular}

Fonte: Bröde et al. (2011). 


\section{Materiais e método}

O estudo está dividido em quatro etapas principais:

(a) monitoramento das variáveis climáticas e obtenção de variáveis pessoais a partir de dados coletados com aplicação de questionários de conforto com a população local em ruas de pedestres;

(b) cálculo da sensação térmica predita através do índice UTCI;

(c) verificação da consistência dos resultados encontrados com o índice; $\mathrm{e}$

(d) proposição de faixas de menor desconforto térmico para o UTCI.

\section{Caracterização climática da área de estudo}

Curitiba situa-se na região Sul do Brasil, latitude $25^{\circ} 31^{\prime}$ Sul, longitude $49^{\circ} 11^{\prime}$ Oeste e altitude média de 917 m. O clima de Curitiba é classificado como subtropical, mesotérmico controlado por massas de ar tropicais e polares, sendo, segundo a classificação Koeppen-Geiger, do tipo $\mathrm{Cfb}$ com verão fresco. Fevereiro é o mês mais quente, com temperatura média de $22{ }^{\circ} \mathrm{C}$, podendo ocorrer temperaturas superiores a $35^{\circ} \mathrm{C}$, e junho é em geral o mês mais frio, com temperatura média de $18{ }^{\circ} \mathrm{C}$, podendo ocorrer temperaturas de até $-5^{\circ} \mathrm{C}$. A temperatura média anual é de $16,5^{\circ} \mathrm{C}$. A cidade apresenta grande amplitude térmica diária e sazonal, com média anual de $16^{\circ} \mathrm{C}$, e chuvas bem distribuídas ao longo do ano, com maior concentração no verão. Entretanto, devido à frente polar atlântica, o inverno pode tornar-se chuvoso. Agosto é o mês mais seco e julho o mês com menos dias de chuva (DANNI-OLIVEIRA, 1999; MENDONÇA, 2001).

\section{Obtenção das variáveis climáticas e pessoais}

A área de estudo localiza-se no centro da cidade de Curitiba, especificamente os trechos de pedestres das Ruas XV de Novembro e Saldanha Marinho (implantadas no sentido SW-NE, com azimute do eixo da rua de $22^{\circ} \mathrm{N}$ ), da Travessa Oliveira Bello e da Rua Senador Alencar Guimarães, que são paralelas (orientação axial NO-SE), e da Praça Generoso Marques.

O calçadão da Rua XV de Novembro (Figura 1) faz parte da história do urbanismo brasileiro por ter-se tornado em 1972 a primeira rua de pedestres do país. Atualmente, a Rua das Flores, como é popularmente chamada, faz parte da identidade cultural da cidade, sendo caracterizada por um fluxo intenso e constante de transeuntes. Segundo a Associação Comercial do Paraná cerca de 140.000 pessoas circulam por dia pelo calçadão. Desde seu surgimento, a via é uma das principais artérias comerciais da cidade.

Foram realizadas medições das condições microclimáticas para pares de pontos com características urbanas diferentes, isto é, medições em cânions largos, cânions estreitos, praças e cruzamentos (Tabela 2). Concomitantemente às medições objetivas, foram aplicados questionários de conforto (conforme a ISO 10551 (INTERNATIONAL..., 1995)), envolvendo questões relativas à sensação térmica dos transeuntes. A Figura 2 mostra a localização dos pontos monitorados.

Foram utilizadas duas estações meteorológicas da marca HOBO modelo H21-001 no monitoramento das variáveis climáticas. Cada estação estava equipada com os seguintes instrumentos:

(a) sensor de temperatura e umidade (S-THBM002);

(b) piranômetro de silício (S-LIB-M003); e

(c) sensor de direção e velocidade do vento (SWCA-M003).
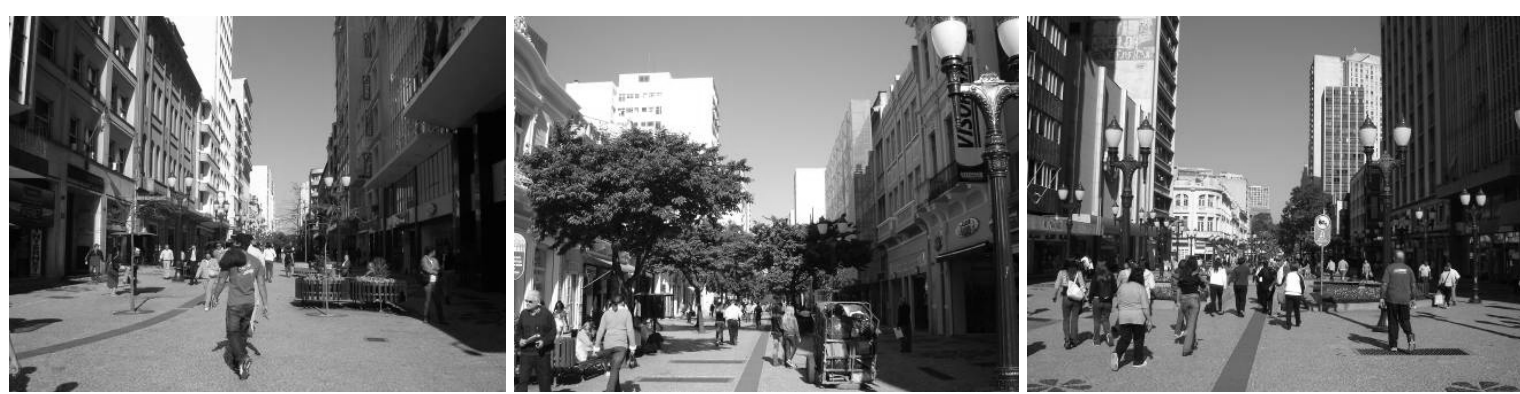

Figura 1 - Fotos da Rua XV de Novembro 
Tabela 2 - Pares de pontos monitorados e características urbanas

\begin{tabular}{c|c|c|c|l|l}
\hline Dia & Ponto & H/W & FVC & Classificação & \multicolumn{1}{|c}{ Observações } \\
\hline \multirow{2}{*}{09.01 .2009} & 2 & 1,7 & 0,20 & cânion estreito & presença de poucas árvores isoladas \\
& 7 & 0,8 & 0,39 & cânion largo & presença de poucas árvores isoladas \\
\hline \multirow{2}{*}{19.03 .2009} & 10 & 1,1 & 0,30 & cânion largo & presença de poucas árvores isoladas \\
& 3 & 1,1 & 0,32 & cânion largo & presença de árvores na quadra toda \\
\hline \multirow{2}{*}{25.03 .2009} & 10 & 1,1 & 0,30 & cânion largo & presença de poucas árvores isoladas \\
& 3 & 1,1 & 0,32 & cânion largo & presença de árvores na quadra toda \\
\hline \multirow{2}{*}{01.04 .2009} & 13 & 2,3 & 0,21 & cânion estreito & sem vegetação \\
& 2 & 1,7 & 0,20 & cânion estreito & presença de poucas árvores isoladas \\
\hline \multirow{2}{*}{08.04 .2009} & 4 & - & 0,34 & cruzamento & edificações nas esquinas \\
& 9 & 1,1 & 0,29 & cânion largo & sem vegetação, trânsito de veículos \\
\hline \multirow{2}{*}{03.06 .2009} & 4 & - & 0,34 & cruzamento & edificações nas esquinas \\
& 14 & - & 0,55 & praça & sem vegetação, fonte d'água \\
\hline \multirow{2}{*}{05.06 .2009} & 10 & 1,1 & 0,30 & cânion largo & presença de poucas árvores isoladas \\
& 5 & 1,6 & 0,22 & cânion estreito & presença de poucas árvores isoladas \\
\hline \multirow{2}{*}{09.06 .2009} & 17 & 1,6 & 0,21 & cânion estreito & sem vegetação \\
& 18 & 1,1 & 0,30 & cânion largo & sem vegetação \\
\hline \multirow{2}{*}{17.06 .2009} & 6 & 1,3 & 0,26 & cânion largo & sem vegetação, fonte d'água \\
& 2 & 1,7 & 0,20 & cânion estreito & presença de poucas árvores \\
\hline \multirow{2}{*}{19.06 .2009} & 3 & 1,1 & 0,32 & cânion largo & presença de árvores na quadra toda \\
& 7 & 0,8 & 0,39 & cânion largo & presença de poucas árvores isoladas \\
\hline \multirow{2}{*}{13.07 .2009} & 8 & - & 0,37 & cruzamento & edificações nas esquinas \\
& 16 & - & 0,38 & praça & presença de poucas árvores isoladas \\
\hline \multirow{2}{*}{11.08 .2009} & 11 & - & 0,20 & praça & presença de vegetação, fonte d'água \\
& 14 & - & 0,55 & praça & sem vegetação, fonte d'água \\
\hline \multirow{2}{*}{12.08 .2009} & 11 & - & 0,20 & praça & presença de vegetação, fonte d'água \\
& 6 & 1,3 & 0,27 & cânion largo & sem vegetação, fonte d'água \\
\hline
\end{tabular}

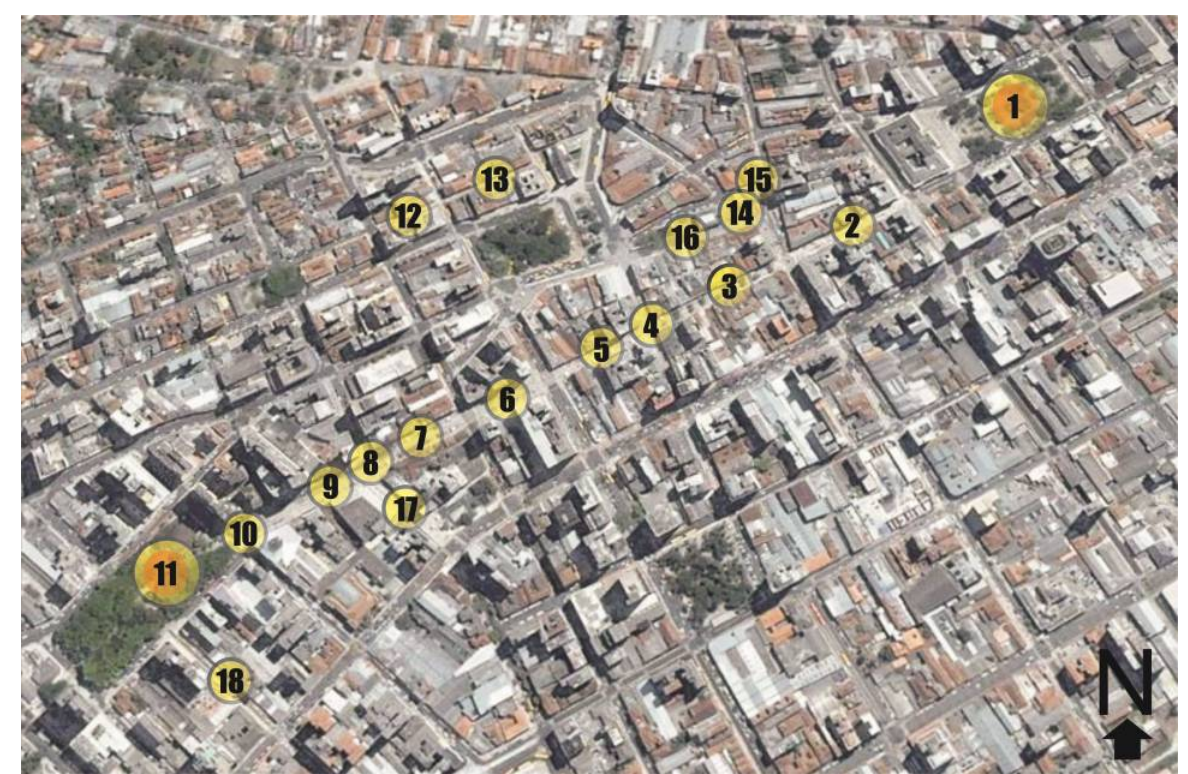

Figura 2 - Localização dos pontos selecionados para o monitoramento das variáveis climáticas e aplicação dos questionários

As faixas de precisão desses instrumentos satisfazem as recomendações da norma ISO 7726 (INTERNATIONAL..., 1998), que dispõe sobre os instrumentos para a medição de variáveis físicas. Os sensores de temperatura do ar e umidade relativa foram fixados na altura de $110 \mathrm{~cm}$, conforme a ISO 7726 (INTERNATIONAL..., 1998). O piranômetro foi fixado a $160 \mathrm{~cm}$. O anemômetro foi fixado a $210 \mathrm{~cm}$, conforme recomendado pelo manual da Campbell (1997). 
Para obter-se a temperatura radiante média, foram utilizados termômetros de globo de cobre, fixados na altura de $110 \mathrm{~cm}$, com $\varnothing=2 "$ (emissividade aproximada do globo $=0,95)$, pintados na cor RAL-7001 (cinza-médio) (THORSSON et al., 2007), devido a sua absorção de radiação de onda curta ser semelhante à de pessoas vestidas, em torno de 0,70 . Os globos estavam equipados com dois sensores de temperatura do tipo sonda, 12-Bit (S-TMB-M002) e HOBO Pro V2 logger (U23004). Os dados foram coletados de $5 \mathrm{~s}$ em $5 \mathrm{~s}$ e depois trabalhados para compor o minuto. A Trm foi calculada pela fórmula para convecção forçada, definida pelas ISO 7726 (INTERNATIONAL..., 1998), apresentada a seguir:

$\operatorname{Trm}=\left\{(\mathrm{Tg}+273)^{4}+\left[\left(1,1 \times 10^{8} \times \mathrm{Va}^{0,6}\right) /(\varepsilon g \mathrm{x}\right.\right.$ $\left.\left.\left.\mathrm{D}^{0,4}\right)\right] \times(\mathrm{Tg}-\mathrm{Ta})\right\} 1 / 4-273$

Eq. 1

Onde:

Trm $=$ temperatura radiante média, $\mathrm{em}{ }^{\circ} \mathrm{C}$;

$\mathrm{Tg}=$ temperatura de globo, em ${ }^{\circ} \mathrm{C}$;

$\mathrm{va}=$ velocidade do vento, $\mathrm{em} \mathrm{m} / \mathrm{s}$;

$\varepsilon \mathrm{g}=$ emissividade do globo (adimensional);

$\mathrm{D}=$ diâmetro do globo, em metros; e

$\mathrm{Ta}=$ temperatura do ar, em ${ }^{\circ} \mathrm{C}$.

Foram monitorados 14 dias entre os meses de janeiro e agosto de 2009, durante 5 h cada dia (das $10 \mathrm{~h} 00$ às $14 \mathrm{~h} 59$ ), sendo dois pontos monitorados simultaneamente em cada dia, perfazendo 28 situações urbanas diferentes. A Tabela 3 mostra a descrição estatística dos dados climáticos. Obtevese uma variação climática bastante considerável em relação à temperatura; por exemplo, tem-se uma variação de $6,4{ }^{\circ} \mathrm{C}$ a $32,6{ }^{\circ} \mathrm{C}$. O total de horas de monitoramento no espaço urbano foi de aproximadamente 70 .

Para a obtenção das variáveis pessoais e de sensação térmica, foram aplicados questionários elaborados a partir da norma internacional ISO 10551 (INTERNATIONAL..., 1995). As variáveis pessoais levantadas foram (1) sexo, (2) idade, (3) altura, (4) peso, (5) tempo de moradia na cidade (fator aclimatação), (6) vestimenta e (7) tempo de exposição ao ambiente externo, além das variáveis sobre percepção térmica. Somente moradores de Curitiba e Região Metropolitana residindo há pelo menos 6 meses foram considerados. As recomendações da ASHRAE Standard 55 (AMERICAN..., 2004) foram seguidas, e somente as pessoas que declararam estar há pelo menos 15 min ao ar livre foram consideradas para as análises, obtendo-se, assim, um total de 1.654 questionários válidos.

Para obter os resultados referentes à percepção térmica (sensação térmica), "Como você se sente neste exato momento?", utilizou-se a escala simétrica de sete graus e dois polos: de -3 (muito frio) a +3 (muito calor), sendo 0 (nem frio nem calor) o ponto neutro.

\section{Obtenção da sensação térmica pelo índice UTCI}

O cálculo da sensação térmica predita através do índice UTCI utilizou-se do modelo UTCI-Fiala (FIALA et al., 2011). Para calcular o UTCI são necessários valores de velocidade do vento medidos a $10 \mathrm{~m}$ de altura. Como os valores monitorados em Curitiba foram obtidos a 2,10 m, foi aplicado um fator de escala segundo a expressão (BRÖDE et al., 2011):

$\mathrm{va}=\operatorname{vaxm} \cdot \log (10 / 0,01) / \log (\mathrm{x} / 0,01)$

Eq. 2

Onde:

$\mathrm{va}=$ velocidade do vento a $10 \mathrm{~m}$ de altura, em $\mathrm{m} / \mathrm{s}$; $\mathrm{e}$

vaxm $=$ velocidade do vento medida a $\mathrm{x}$ metros, $\mathrm{em} \mathrm{m} / \mathrm{s}$.

No caso desta pesquisa, a velocidade do vento foi medida a 2,10 m, assim, $\mathrm{x}$ é substituído por 2,10 $\mathrm{m}$, obtendo-se o fator de escala 1,29. As variáveis de entrada para o cálculo do UTCI são as seguintes: Va10 (m/s), Ta $\left({ }^{\circ} \mathrm{C}\right)$ UR $(\%)$ e Trm - Ta $\left({ }^{\circ} \mathrm{C}\right)$. A taxa metabólica é assumida como constante e igual a $150 \mathrm{~W} / \mathrm{m} 2$ ou 2,6 met (pessoa caminhando a $4 \mathrm{~km} / \mathrm{h}$ em terreno plano), e o grau de isolamento térmico da vestimenta é atribuído a partir da temperatura do ar com base em observações empíricas em estudos de campo europeus.

Tabela 3 - Descrição estatística dos dados climáticos

\begin{tabular}{l|c|c|c|c|c|c}
\hline & Va (m/s) & RS $\left(\mathbf{W} / \mathbf{m}^{2}\right)$ & Ta $\left({ }^{\mathbf{0}} \mathbf{C}\right)$ & UR (\%) & Tg $\left({ }^{\mathbf{0}} \mathbf{C}\right)$ & Trm $\left({ }^{\mathbf{0}} \mathbf{C}\right)$ \\
\hline Média & 1,1 & 298 & 19,4 & 56 & 21,9 & 30,1 \\
\hline Mínimo & 0,0 & 1 & 6,4 & 23 & 7,6 & 8,6 \\
\hline Máximo & 4,2 & 1.249 & 32,6 & 93 & 38,0 & 74,7 \\
\hline Desvio padrão & 0,6 & 309 & 5,4 & 13 & 6,6 & 13,5 \\
\hline Variância & 0,4 & 95.451 & 29,4 & 172 & 43,0 & 182,0 \\
\hline
\end{tabular}


Aplicou-se o modelo-base de vestimenta embutido no UTCI para o presente trabalho, uma vez que, em uma comparação anterior utilizando o modelobase e desenvolvendo o cálculo do índice a partir de dados de vestimenta obtidos durante o trabalho de campo (anotou-se peça por peça a vestimenta de cada entrevistado, conforme indicações em uma lista contendo trajes de verão e inverno, segundo a ISO 9920 (INTERNATIONAL..., 2007)), observou-se pequena, mas significativa melhoria na estimativa da sensação térmica pelo UTCI ao adotar-se o modelo-base (BRÖDE; KRÜGER; ROSSI, 2011).

\section{Verificação da consistência dos resultados}

Para testar a consistência dos resultados obtidos com o UTCI, agruparam-se os dados pessoais da seguinte forma:

(a) sexo: homem e mulher;

(b) idade:

- jovem = até 25 anos;

- adulto $=$ entre 25 e 64 anos; e

- idoso = acima de 64 anos (WORLD..., 1995);

(c) IMC (índice de massa corpórea, em $\mathrm{kg} / \mathrm{m}^{2}$ ):

- abaixo do peso (IMC $<18,5)$;

- normal $(18,5 \leq \mathrm{BMI}<25)$;

- sobrepeso $(25 \leq \mathrm{BMI} \leq 30)$; e

- obeso (BMI > 30), aplicado às pessoas acima de 20 anos (WORLD..., 1995; WORLD..., 2004).

Os valores de IMC para pessoas até 20 anos foram agrupados conforme os gráficos de crescimento da CDC (Centers for Disease Control and Prevention) (KUCZMARSKI et al., 2002).

Comparações foram feitas para os meses quentes (janeiro a maio) e frios (junho a agosto) da série de dados monitorados.

Para verificar a relação entre a temperatura ambiente e o UTCI de forma não linear, foi aplicada a função de alisamento estimada (estimated smoothing functions - LOESS), de forma a descrever o comportamento médio do isolamento térmico da roupa e da sensação térmica com $95 \%$ de confiança para toda a amostra, assim como para os subgrupos definidos por sexo e época do ano. Para analisar o grau de ajuste da curva, os erros da predição da sensação térmica, para toda a amostra e para os subgrupos, foram avaliados pelo erro médio ou diferença entre a sensação térmica predita e a sensação térmica real, pelo valor quadrático médio do erro (RMSE - root mean square error) e pelo coeficiente de correlação de Pearson (R) entre o valor observado e o valor predito.

\section{Proposição de faixas de menor desconforto térmico para o UTCI}

Foram realizadas duas análises:

(a) análises das respostas de sensação térmica reais e as preditas pelo índice UTCI; e

(b) a porcentagem estimada de insatisfeitos com o ambiente analisado para as respostas reais e para o UTCI.

Para tais análises, os dados reais e preditos foram agrupados em três categorias:

(a) desconforto para o frio;

(b) conforto; e

(c) desconforto para o calor, conforme a classificação abaixo:

- desconforto para o frio: votos -3 e -2;

- conforto: votos $-1,0$ e +1 ; e

- desconforto para o calor: votos $+2 \mathrm{e}+3$.

Foram aplicadas duas classificações para a sensação térmica predita pelo UTCI, adotando-se os valores-limite das faixas definidas pelo índice. A Tabela 1 mostra duas faixas que podem ser consideradas como conforto térmico; a primeira delas, chamada "conforto térmico", abrange as temperaturas UTCI de $18{ }^{\circ} \mathrm{C}$ a $26{ }^{\circ} \mathrm{C}$; e a segunda, denominada "sem estresse térmico", abrange as temperaturas UTCI de $9{ }^{\circ} \mathrm{C}$ a $18^{\circ} \mathrm{C}$.

Considerando que a faixa definida pela combinação das duas categorias de estresse, isto é, de $9{ }^{\circ} \mathrm{C}$ a $26{ }^{\circ} \mathrm{C}$, pode ser considerada como conforto térmico, decidiu-se fazer a comparação entre a faixa menos abrangente, definida como conforto térmico pelo índice $\left(18{ }^{\circ} \mathrm{C}\right.$ a $\left.26{ }^{\circ} \mathrm{C}\right)$, e a faixa mais abrangente $\left(9{ }^{\circ} \mathrm{C}\right.$ a $\left.26^{\circ} \mathrm{C}\right)$. Dessa forma, têm-se as seguintes classificações para os votos preditos.

Classificação A para a sensação térmica predita pelo UTCI:
(a) desconforto para o frio: $\mathrm{UTCI}<18^{\circ} \mathrm{C}$;
(b) conforto: $18^{\circ} \mathrm{C} \leq \mathrm{UTCI} \leq 26^{\circ} \mathrm{C}$; e
(c) desconforto para o calor: UTCI $>26^{\circ} \mathrm{C}$.

Classificação B para a sensação térmica predita pelo UTCI:
(a) desconforto para o frio: $\mathrm{UTCI}<9{ }^{\circ} \mathrm{C}$;
(b) conforto: $9^{\circ} \mathrm{C} \leq \mathrm{UTCI} \leq 26^{\circ} \mathrm{C}$; e
(c) desconforto para o calor: UTCI $>26^{\circ} \mathrm{C}$. 
Para todas as situações acima, foram gerados gráficos de dispersão em função da temperatura do ar (Ta) e da diferença entre temperatura radiante média e da temperatura do ar (Trm-Ta). A partir dos gráficos, analisaram-se as nuvens de pontos para cada uma das categorias de sensação térmica (desconforto para o frio, conforto e desconforto para o calor) para uma definição inicial das faixas de desconforto térmico. Para a análise da porcentagem estimada de insatisfeitos, utilizou-se o conceito PPD proposto por Fanger (1982). Os votos de sensação térmica (de $-3 \quad a+3)$ foram agrupados para a variação de um grau de temperatura equivalente UTCI, segundo procedimento sugerido por de Dear e Fountain (1994), verificando-se o percentual de votos em conforto e desconforto para cada grau de variação de UTCI.

Para o cálculo da porcentagem teórica de pessoas insatisfeitas com o ambiente foi utilizada a fórmula proposta por Fanger (ISO 7730 (INTERNATIONAL..., 2005)).

$\mathrm{PPD}=100-95^{*} \exp \left(-0,03353^{*} \mathrm{PMV}^{4}\right.$ $0,2179 * \mathrm{PMV}^{2}$ )

Eq. 3

A Tabela 4 apresenta a quantidade de pessoas em conforto e desconforto para cada grau de temperatura na escala UTCI, o voto equivalente de sensação térmica para cada grau de variação, a quantidade de respondentes por cada faixa $(\mathrm{N})$ e a porcentagem estimada de insatisfeitos calculada segundo a Eq. 3 .

Tabela 4 - Porcentagem de pessoas em conforto e desconforto por grau de temperatura UTCI

\begin{tabular}{|c|c|c|c|c|c|}
\hline UTCI & $\begin{array}{c}\text { Conforto } \\
(\%)\end{array}$ & $\begin{array}{c}\text { Desconforto } \\
(\%) \\
\end{array}$ & $\begin{array}{l}\text { Voto equivalente de } \\
\text { sensação térmica }\end{array}$ & $\mathbf{N}$ & $\begin{array}{l}\text { PPD } \\
(\%) \\
\end{array}$ \\
\hline 3,0 a $3,9^{\circ} \mathrm{C}$ & 0 & 100 & $-2,0$ & 1 & 77 \\
\hline 6,0 a $6,9^{\circ} \mathrm{C}$ & 0 & 100 & $-2,0$ & 1 & 77 \\
\hline 7,0 a $7,9^{\circ} \mathrm{C}$ & 100 & 0 & $-1,0$ & 1 & 26 \\
\hline 8,0 a $8,9^{\circ} \mathrm{C}$ & 67 & 33 & $-0,8$ & 6 & 20 \\
\hline 9,0 a $9,9^{\circ} \mathrm{C}$ & 67 & 33 & $-1,2$ & 18 & 36 \\
\hline 10,0 a $10,9^{\circ} \mathrm{C}$ & 67 & 33 & $-1,1$ & 51 & 31 \\
\hline 11,0 a $11,9^{\circ} \mathrm{C}$ & 63 & 37 & $-1,1$ & 30 & 32 \\
\hline 12,0 a $12,9^{\circ} \mathrm{C}$ & 84 & 16 & $-0,9$ & 43 & 21 \\
\hline 13,0 a $13,9^{\circ} \mathrm{C}$ & 83 & 18 & $-0,5$ & 40 & 10 \\
\hline 14,0 a $14,9^{\circ} \mathrm{C}$ & 84 & 16 & $-0,6$ & 49 & 13 \\
\hline 15,0 a $15,9^{\circ} \mathrm{C}$ & 81 & 19 & $-0,5$ & 70 & 11 \\
\hline 16,0 a $16,9^{\circ} \mathrm{C}$ & 83 & 17 & $-0,4$ & 93 & 8 \\
\hline 17,0 a $17,9^{\circ} \mathrm{C}$ & 92 & 8 & $-0,2$ & 89 & 6 \\
\hline 18,0 a $18,9^{\circ} \mathrm{C}$ & 93 & 7 & 0,0 & 73 & 5 \\
\hline 19,0 a $19,9^{\circ} \mathrm{C}$ & 97 & 3 & 0,2 & 70 & 6 \\
\hline 20,0 a $20,9^{\circ} \mathrm{C}$ & 95 & 5 & $-0,2$ & 65 & 6 \\
\hline 21,0 a $21,9^{\circ} \mathrm{C}$ & 91 & 9 & 0,0 & 104 & 5 \\
\hline 22,0 a $22,9^{\circ} \mathrm{C}$ & 93 & 7 & $-0,2$ & 69 & 6 \\
\hline 23,0 a $23,9^{\circ} \mathrm{C}$ & 94 & 6 & 0,2 & 62 & 6 \\
\hline 24,0 a $24,9^{\circ} \mathrm{C}$ & 92 & 8 & 0,2 & 100 & 6 \\
\hline 25,0 a $25,9^{\circ} \mathrm{C}$ & 79 & 21 & 0,4 & 63 & 8 \\
\hline 26,0 a $26,9^{\circ} \mathrm{C}$ & 78 & 22 & 0,5 & 112 & 11 \\
\hline 27,0 a $27,9^{\circ} \mathrm{C}$ & 69 & 31 & 1,0 & 100 & 25 \\
\hline 28,0 a $28,9^{\circ} \mathrm{C}$ & 70 & 30 & 1,0 & 46 & 27 \\
\hline 29,0 a $29,9^{\circ} \mathrm{C}$ & 57 & 43 & 1,2 & 44 & 34 \\
\hline 30,0 a $30,9^{\circ} \mathrm{C}$ & 71 & 29 & 1,0 & 69 & 27 \\
\hline 31,0 a $31,9^{\circ} \mathrm{C}$ & 71 & 29 & 1,1 & 58 & 29 \\
\hline 32,0 a $32,9^{\circ} \mathrm{C}$ & 53 & 47 & 1,5 & 59 & 50 \\
\hline 33,0 a $33,9^{\circ} \mathrm{C}$ & 39 & 61 & 1,7 & 46 & 59 \\
\hline 36,0 a $36,9^{\circ} \mathrm{C}$ & 57 & 43 & 1,5 & 23 & 52 \\
\hline 35,0 a $35,9^{\circ} \mathrm{C}$ & 19 & 81 & 2,1 & 21 & 81 \\
\hline 36,0 a $36,9^{\circ} \mathrm{C}$ & 22 & 78 & 1,8 & 9 & 66 \\
\hline 3,0 a $3,9^{\circ} \mathrm{C}$ & 0 & 100 & $-2,0$ & 1 & 77 \\
\hline
\end{tabular}

48 Rossi, F. A.; Krüger, E. L.; Bröde, P. 


\section{Análise de resultados}

\section{Verificação da consistência dos dados}

A Figura 3 mostra a distribuição das variáveis climáticas, velocidade do vento (Figura 3a) e umidade relativa (Figura 3b), em função da temperatura do ar. A velocidade do vento (Figura 3a) apresenta uma variação constante com média aproximada de $1 \mathrm{~m} / \mathrm{s}$. A curva alisada da umidade relativa (Figura $3 \mathrm{~b}$ ) está entre os valores de $50 \%$ e $60 \%$, verificando-se que, em temperaturas mais elevadas, a curva sofre um desvio para a pressão de vapor próxima a $20 \mathrm{hPa}$.

Na Figura 4 está representada a distribuição do isolamento térmico da vestimenta em função da temperatura do ar. Foi traçada a curva da função de alisamento estimada (LOESS) (linhas tracejadas) com $95 \%$ de intervalo de confiança para toda a amostra (Figura 4a) e para o período definido como o mais frio e para o período definido como o mais quente (Figura 4b). As linhas pretas representam o isolamento térmico da vestimenta conforme predito pelo modelo UTCI.

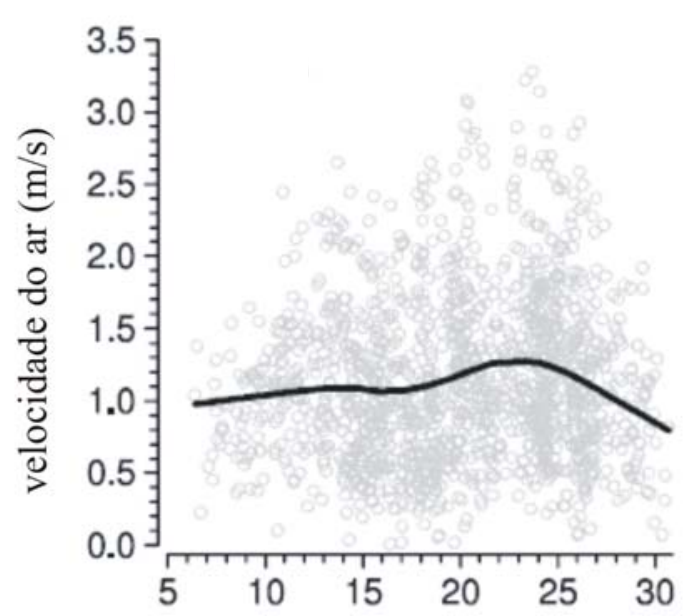

(a) temperatura do $\operatorname{ar}\left({ }^{\circ} \mathrm{C}\right)$

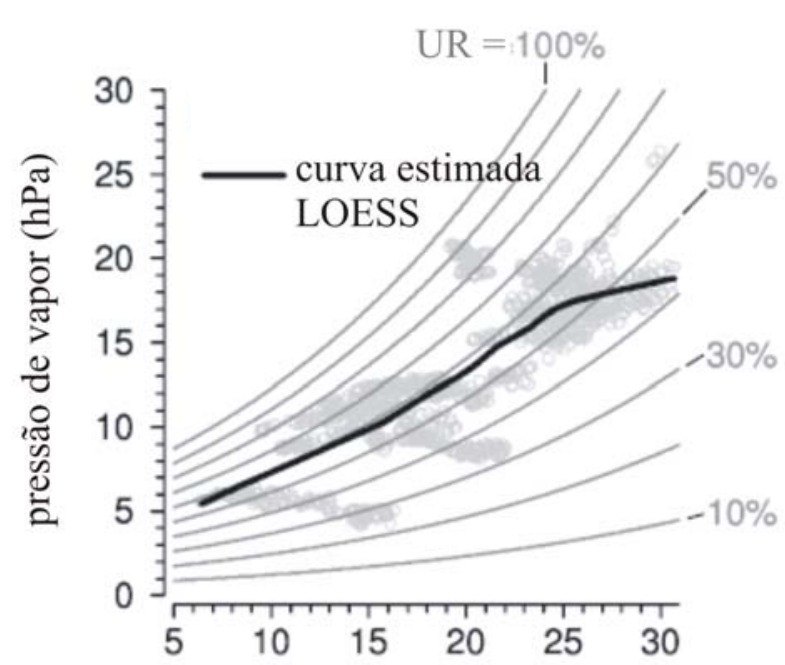

(b) temperatura do $\operatorname{ar}\left({ }^{\circ} \mathrm{C}\right)$

Figura 3 - Gráficos de dispersão da distribuição da velocidade do vento monitorada (a) e umidade relativa monitorada (b), em função da temperatura do ar com a curva alisada estimada (LOESS)

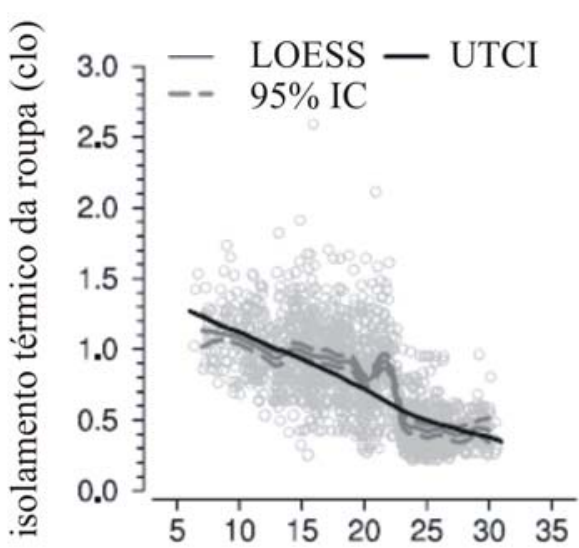

(a) temperatura do ar $\left({ }^{\circ} \mathrm{C}\right)$

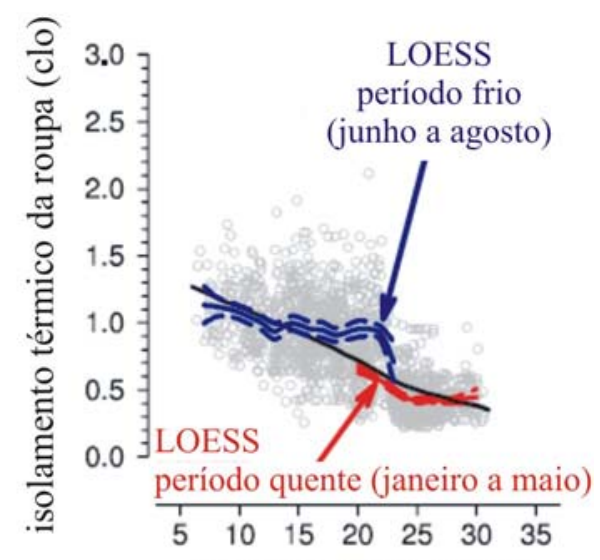

(b) temperatura do ar $\left({ }^{\circ} \mathrm{C}\right)$

Figura 4 - Gráficos de dispersão da distribuição do isolamento térmico da vestimenta para toda a amostra (a) e para o período mais frio e mais quente (b) em função da temperatura do ar

Nota: as linhas tracejadas representam a curva estimada (LOESS) para o intervalo de confiança de $95 \%$ e as linhas sólidas indicam o isolamento térmico da vestimenta assumido pelo índice UTCI. 
O isolamento térmico da vestimenta diminui com o aumento da temperatura do ar e apresenta uma grande variação para cada indivíduo, sendo tal variação menor nos limites extremos da temperatura do ar (Figura 4a). A curva mostra uma boa concordância entre os valores preditos pelo UTCI e os observados, porém apresenta um desvio de aproximadamente 0,2 clo a $20{ }^{\circ} \mathrm{C}$ de temperatura do ar e uma acentuada diminuição do isolamento térmico em altas temperaturas, quando comparado com os valores preditos pelo UTCI. Da mesma forma, ao analisar os períodos de inverno e de verão separadamente (Figura 4b), nota-se um grande desvio em situações de alto isolamento térmico associado a temperaturas próximas de 20 ${ }^{\circ} \mathrm{C}$.

A Figura 5 apresenta os valores observados e preditos pelo UTCI de isolamento térmico da vestimenta, com a curva da função de alisamento estimada (LOESS) para 95\% de intervalo de confiança para toda a amostra (Figura 5a) e por sexo (Figura 5b), feminino (710 mulheres) e masculino (944 homens). A análise da Figura 5a mostra que o isolamento térmico definido pelo UTCI está predominantemente dentro do intervalo de confiança dos valores observados. Entretanto, um desvio de 0,1 clo ocorre entre os valores de temperatura equivalente de 16 a $22{ }^{\circ} \mathrm{C}$. Ao comparar o comportamento em relação à vestimenta entre homens e mulheres (Figura 5b), observa-se que as mulheres escolhem menos

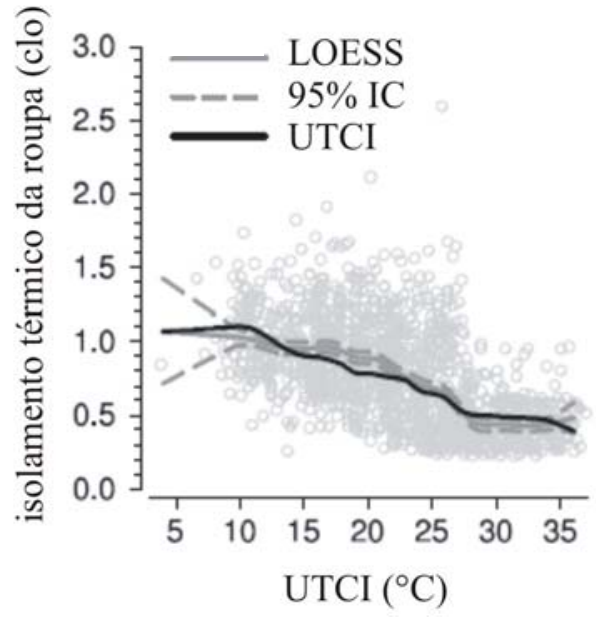

(a) Para toda a amostra isolamento térmico que os homens em condições quentes, com UTCI acima de $24^{\circ} \mathrm{C}$.

A Figura 6 apresenta os votos de sensação térmica reais comparativamente a valores em UTCI. A curva da função de alisamento estimada (LOESS) para toda a amostra (Figura 6a) sugere que, em média, a sensação térmica neutra para o UTCI ocorre entre os valores $18{ }^{\circ} \mathrm{C}$ e $23{ }^{\circ} \mathrm{C}$. O aumento da sensação térmica em valores acima de $23{ }^{\circ} \mathrm{C}$ e sua diminuição em valores abaixo de $18{ }^{\circ} \mathrm{C}$ são aproximadamente lineares e não apresentam diferença significativa entre homens e mulheres (Figura 6b).

A Tabela 4 resume os resultados de viés (bias), os valores quadráticos médios dos erros (RMSE) e o coeficiente de correlação de Pearson (R) obtidos para os subgrupos sexo, idade, índice de massa corpórea e época do ano. As diferenças de sensação térmica relacionadas ao sexo são insignificantes. Em relação à idade, os valores para os jovens mostraram correlações mais altas comparativamente às dos grupos de adultos e idosos. Em relação à composição corporal, houve um aumento do viés (bias) e do RMSE, e a diminuição da correlação $\mathrm{R}$ dos subgrupos "magro" e "normal" para os subgrupos "sobrepeso" e "obeso" respectivamente. Um aumento similar do viés (bias) foi observado para pessoas entrevistadas durante o período mais frio. No entanto, as diferenças em geral entre os subgrupos foram pequenas, com o erro quadrático médio (RMSE) aproximado de 1 ponto.

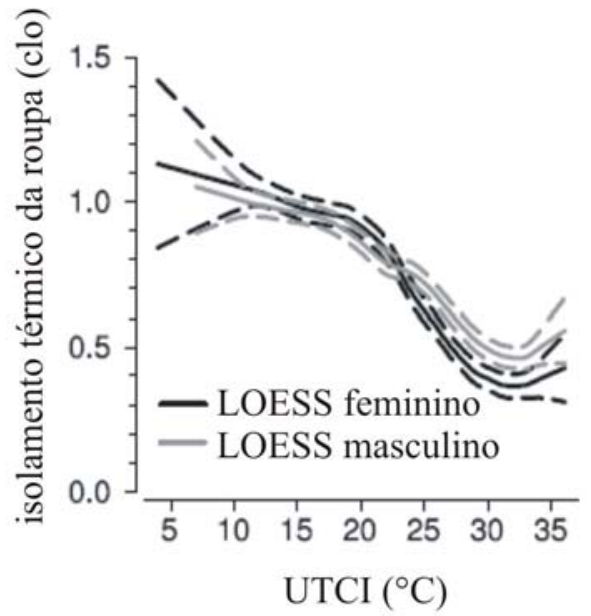

(b) Comparação entre o isolamento térmico feminino e o masculino

Figura 5 - Valores de isolamento térmico da vestimenta observados e curva estimada (LOESS) com intervalo de confiança de $95 \%$ (linhas tracejadas) 


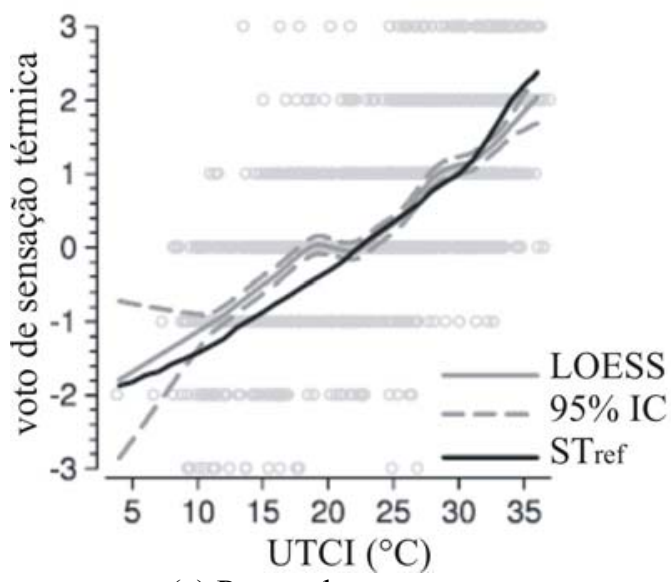

(a) Para toda a amostra

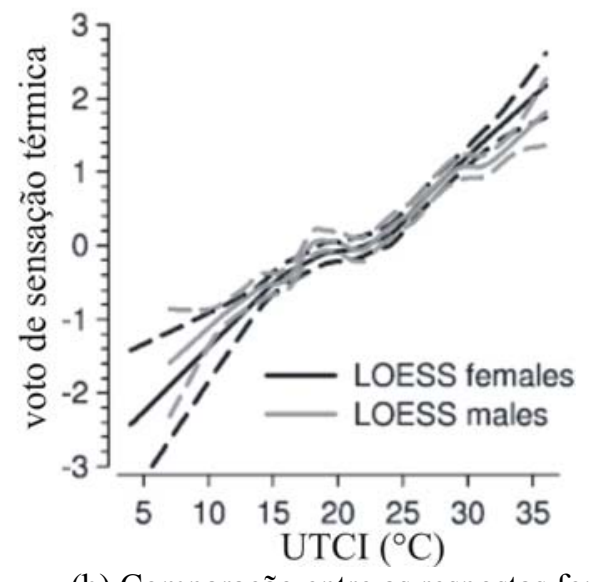

(b) Comparação entre as respostas femininas e as masculinas com curva estimada

Figura 6 - Respostas reais de sensação térmica com a curva estimada (LOESS) e intervalo de confiança de $95 \%$ (linhas tracejadas)

Tabela 4 - Viés, valor quadrático médio dos erros (RMSE) e coeficientes de correlação de Pearson (R) para os diferentes subgrupos

\begin{tabular}{l|l|r|c|c|c}
\hline Subgrupos & & N & Viés & RMSE & R \\
\hline \multirow{2}{*}{ Sexo } & Feminino & 710 & $-0,13$ & 1,02 & 0,61 \\
& Masculino & 944 & $-0,13$ & 0,91 & 0,63 \\
\hline \multirow{3}{*}{ Idade } & Jovem & 494 & $-0,23$ & 0,99 & 0,66 \\
& Adulto & 1.008 & $-0,09$ & 0,94 & 0,61 \\
& Idoso & 152 & $-0,09$ & 0,96 & 0,50 \\
\hline \multirow{4}{*}{ IMC } & Magro & 42 & $-0,06$ & 0,88 & 0,68 \\
& Normal & 897 & $-0,1$ & 0,94 & 0,64 \\
& Sobrepeso & 528 & $-0,16$ & 0,97 & 0,59 \\
\multirow{2}{*}{ Estação } & Obeso & 187 & $-0,23$ & 1,00 & 0,61 \\
\hline & Fria & 880 & $-0,21$ & 0,97 & 0,33 \\
& Quente & 774 & $-0,05$ & 0,94 & 0,51 \\
\hline
\end{tabular}

\section{Análise das respostas de percepção e preditas pelo UTCI}

A partir do agrupamento das respostas de sensação térmica foram traçados gráficos de dispersão para análise do desconforto térmico. $\mathrm{O}$ agrupamento considerou os votos -3 e -2 como desconforto para o frio, os votos $-1,0$ e +1 como conforto, e os votos +2 e +3 como desconforto para o calor (Figura 7). Nota-se que os votos de desconforto para o calor estão concentrados em grande parte (60\% do total em desconforto por calor) em temperatura do ar acima de $23{ }^{\circ} \mathrm{C}$ e com efeito da radiação, ou seja, a maior concentração dos votos ocorre com a diferença entre temperatura radiante média e temperatura do ar acima de $10{ }^{\circ} \mathrm{C}$. A maior parte dos votos de conforto $(56 \%$ do total em conforto) está entre os valores aproximados de temperatura do ar de $13{ }^{\circ} \mathrm{C}$ e $26{ }^{\circ} \mathrm{C}$, com a diferença entre temperatura radiante média $\mathrm{e}$ temperatura do ar até $10{ }^{\circ} \mathrm{C}$, e os votos de desconforto para o frio concentram-se em sua maior parte ( $70 \%$ do total em desconforto por frio) em temperaturas inferiores a $16^{\circ} \mathrm{C}$, com diferença entre temperatura radiante média e temperatura do ar até $10^{\circ} \mathrm{C}$.

Ressalta-se que a análise acima foi feita para todo o período de monitoramento, sem levar em consideração as diferenças térmicas sazonais. Dessa forma, a sobreposição das faixas de desconforto térmico pode ter ocorrido devido à adaptação térmica sazonal. Nikolopoulou e Steemers (2003) afirmam que as pessoas adaptamse psicologicamente em função da exposição repetida a um mesmo estímulo e constroem esquemas mentais que auxiliam na escolha de ações sob diferentes circunstâncias.

A radiação solar, aqui representada pela temperatura radiante média, parece ter importante 
papel na sensação de conforto. De modo geral, pode-se perceber que o desconforto para o calor ocorre quando há altas temperaturas do ar associadas a altos valores de temperatura radiante média. O desconforto para o frio ocorre com baixas temperaturas do ar e baixas temperaturas radiantes médias. Isso sugere que, para atingir o conforto, são necessários moderados valores de temperatura do ar e diferença máxima de $10{ }^{\circ} \mathrm{C}$ entre temperatura radiante média e temperatura do ar.

No que diz respeito à determinação da faixa de conforto e desconforto para o frio e para o calor, pode-se sugerir a seguinte definição de faixas:

(a) desconforto para o frio: temperatura do ar inferior a $16^{\circ} \mathrm{C}$;

(b) conforto: temperatura do ar entre $13{ }^{\circ} \mathrm{C}$ e 23

${ }^{\circ} \mathrm{C}$; e

(c) desconforto por calor: temperatura do ar acima de $23{ }^{\circ} \mathrm{C}$.

A mesma análise foi realizada para os valores preditos pelo UTCI. A Figura 8 apresenta dois agrupamentos, sendo apresentado no Gráfico A o conforto térmico definido pela faixa de $18{ }^{\circ} \mathrm{C}$ a 26 'C UTCI ("conforto térmico", Tabela 1) e no Gráfico B o conforto definido pela faixa de $9{ }^{\circ} \mathrm{C}$ a $26{ }^{\circ} \mathrm{C}$ UTCI ("conforto térmico" e "sem estresse térmico", Tabela 1). O comportamento para a faixa de $18{ }^{\circ} \mathrm{C}$ a $26^{\circ} \mathrm{C}$ Ta é similar ao comportamento obtido pelos votos de sensação térmica (Figura 7). Ao analisarem-se as Figuras 7 e 8, é possível ver uma clara divisão entre as zonas de conforto e desconforto para o frio e para o calor. Para o desconforto por frio a predominância ocorre para valores aproximados de temperatura do ar até 18 ${ }^{\circ} \mathrm{C}$ e temperatura radiante média até $10{ }^{\circ} \mathrm{C}$ acima da temperatura do ar $(85 \%$ do total em desconforto por frio). A faixa de conforto pode ser definida para os valores aproximados de temperatura do ar entre $18{ }^{\circ} \mathrm{C}$ e $24^{\circ} \mathrm{C}$ e diferença entre temperatura radiante média e temperatura do ar de $10^{\circ} \mathrm{C}(53 \%$ do total em conforto). O desconforto para o calor ocorre quando a temperatura radiante média é superior à temperatura do ar, para temperatura do ar acima de $23^{\circ} \mathrm{C}$.

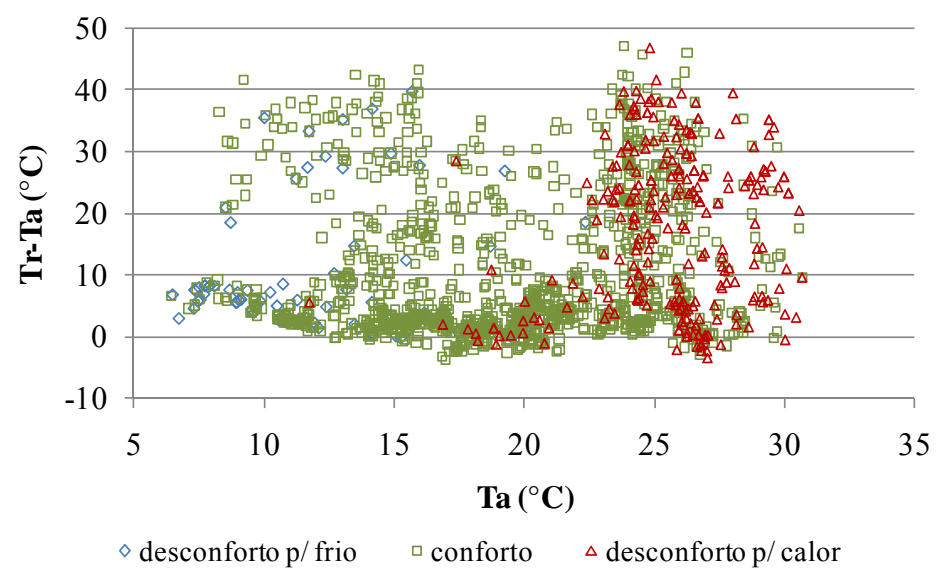

Figura 7 - Distribuição dos votos reais de cada categoria de sensação térmica em função da temperatura do ar e da diferença entre temperatura radiante média e temperatura do ar

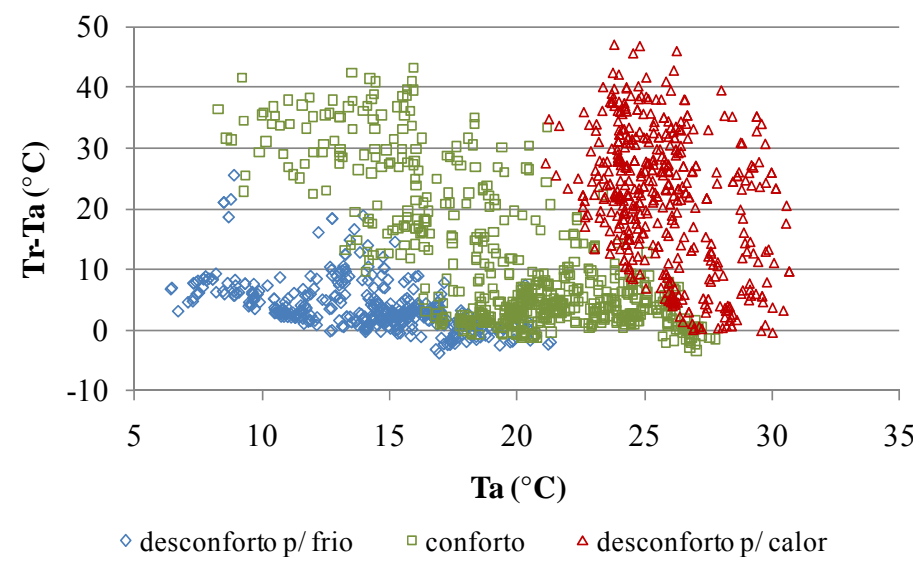

Figura 8 - Votos preditos pelo UTCI, considerando como conforto térmico os valores entre 18 o $\mathrm{C} 26$ oC, classificação A 


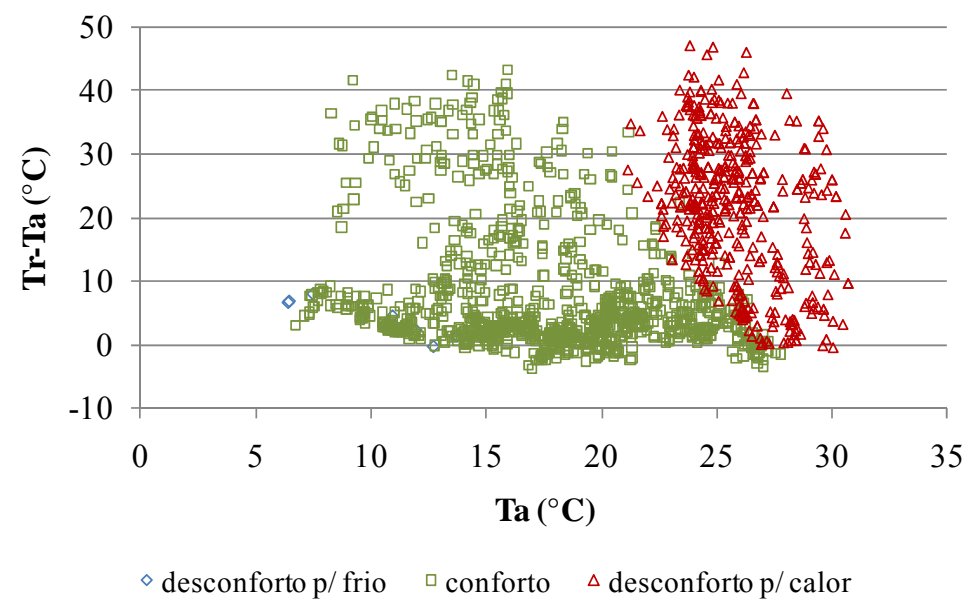

Figura 9 - Votos preditos pelo UTCl, considerando como conforto térmico os valores entre 9 o $\mathrm{C}$ e 26 으, classificação B

Tabela 6 - Faixas de conforto e desconforto para a sensação térmica real e para o índice UTCI

\begin{tabular}{|c|c|c|c|c|c|c|}
\hline & \multicolumn{2}{|c|}{ desconforto para o frio } & \multicolumn{2}{|c|}{ conforto } & \multicolumn{2}{|c|}{ desconforto para o calor } \\
\hline & Ta $\left({ }^{\circ} \mathrm{C}\right)$ & Trm-Ta $\left({ }^{\circ} \mathrm{C}\right)$ & Ta $\left({ }^{\circ} \mathrm{C}\right)$ & Trm-Ta $\left({ }^{\circ} \mathrm{C}\right)$ & Ta $\left({ }^{\circ} \mathrm{C}\right)$ & Trm-Ta $\left({ }^{\circ} \mathrm{C}\right)$ \\
\hline $\begin{array}{l}\text { sensação } \\
\text { térmica }(-1, \\
0 \text { e 1) }\end{array}$ & $\leq 16^{\circ} \mathrm{C}$ & 0 a $10^{\circ} \mathrm{C}$ & 13 a $23^{\circ} \mathrm{C}$ & -5 a $40^{\circ} \mathrm{C}$ & $\geq 23{ }^{\circ} \mathrm{C}$ & -5 a $40^{\circ} \mathrm{C}$ \\
\hline $\begin{array}{l}\text { UTCI (18 } \\
\left.{ }^{\circ} \mathrm{C} \text { e } 26^{\circ} \mathrm{C}\right)\end{array}$ & $<18{ }^{\circ} \mathrm{C}$ & 0 a $10{ }^{\circ} \mathrm{C}$ & 18 a $24^{\circ} \mathrm{C}$ & -5 a $40^{\circ} \mathrm{C}$ & $>24{ }^{\circ} \mathrm{C}$ & -5 a $40^{\circ} \mathrm{C}$ \\
\hline
\end{tabular}

Ao considerar a faixa sem estresse térmico (entre 9 ${ }^{\circ} \mathrm{C}$ e $26{ }^{\circ} \mathrm{C}$ ), o UTCI superestima a quantidade de pessoas em conforto, estando essa faixa entre os valores aproximados de $14{ }^{\circ} \mathrm{C}$ a $21{ }^{\circ} \mathrm{C}$ de temperatura do ar (Figura 9). Como consequência, poucas pessoas estariam em desconforto para o frio $(0,5 \%$ do total de entrevistados). Já para o desconforto para o calor o comportamento não se altera em relação à situação anterior.

Entre as duas situações do UTCI, a que sugere como faixa de conforto térmico a banda entre 18 ${ }^{\circ} \mathrm{C}$ e $26{ }^{\circ} \mathrm{C}$ Ta tem um comportamento mais semelhante com as respostas reais obtidas por meio de questionário. Entretanto, dada a discrepância observada nas faixas ideais $\left(13-23{ }^{\circ} \mathrm{C}\right.$ Ta para sensação real e $18-24{ }^{\circ} \mathrm{C}$ Ta para UTCI), nota-se a necessidade de ajuste dos limites definidos na Tabela 1, considerando a situação subtropical de Curitiba. Tal ajuste já fora sugerido em trabalho anterior (BRÖDE; KRÜGER; ROSSI, 2011). A Tabela 6 apresenta o resumo das faixas de conforto e desconforto obtidas nas análises em função da temperatura do ar e temperatura radiante média.

\section{Proposição de faixas de menor desconforto térmico para 0 UTCl: análise da porcentagem estimada de insatisfeitos}

Definiu-se que as faixas de conforto/desconforto térmico podem ser originadas a partir dos votos de sensação térmica, obtidos por meio de questionário, agrupados da seguinte forma:
(a) desconforto para o frio: votos -3 e -2 ;
(b) conforto: votos $-1,0 \mathrm{e}+1$; e
(c) desconforto para o calor: votos $+2 \mathrm{e}+3$.

A partir desses dados foram contabilizadas as porcentagens de pessoas em conforto e desconforto (Tabela 3) e traçados os gráficos apresentados nas Figuras 10 e 11. Percebe-se que, grosso modo, para percentuais acima de $90 \%$ de pessoas em conforto a faixa ideal seria de $17-25^{\circ} \mathrm{C}$ UTCI; para percentuais acima de $80 \%$ a faixa corresponderia a 12-26 ${ }^{\circ} \mathrm{C}$ UTCI. Para Ta, observa-se que, para acima de $90 \%$ de pessoas em conforto, a faixa seria $17-22{ }^{\circ} \mathrm{C}$; e, para $80 \%, 12-24{ }^{\circ} \mathrm{C}$. 


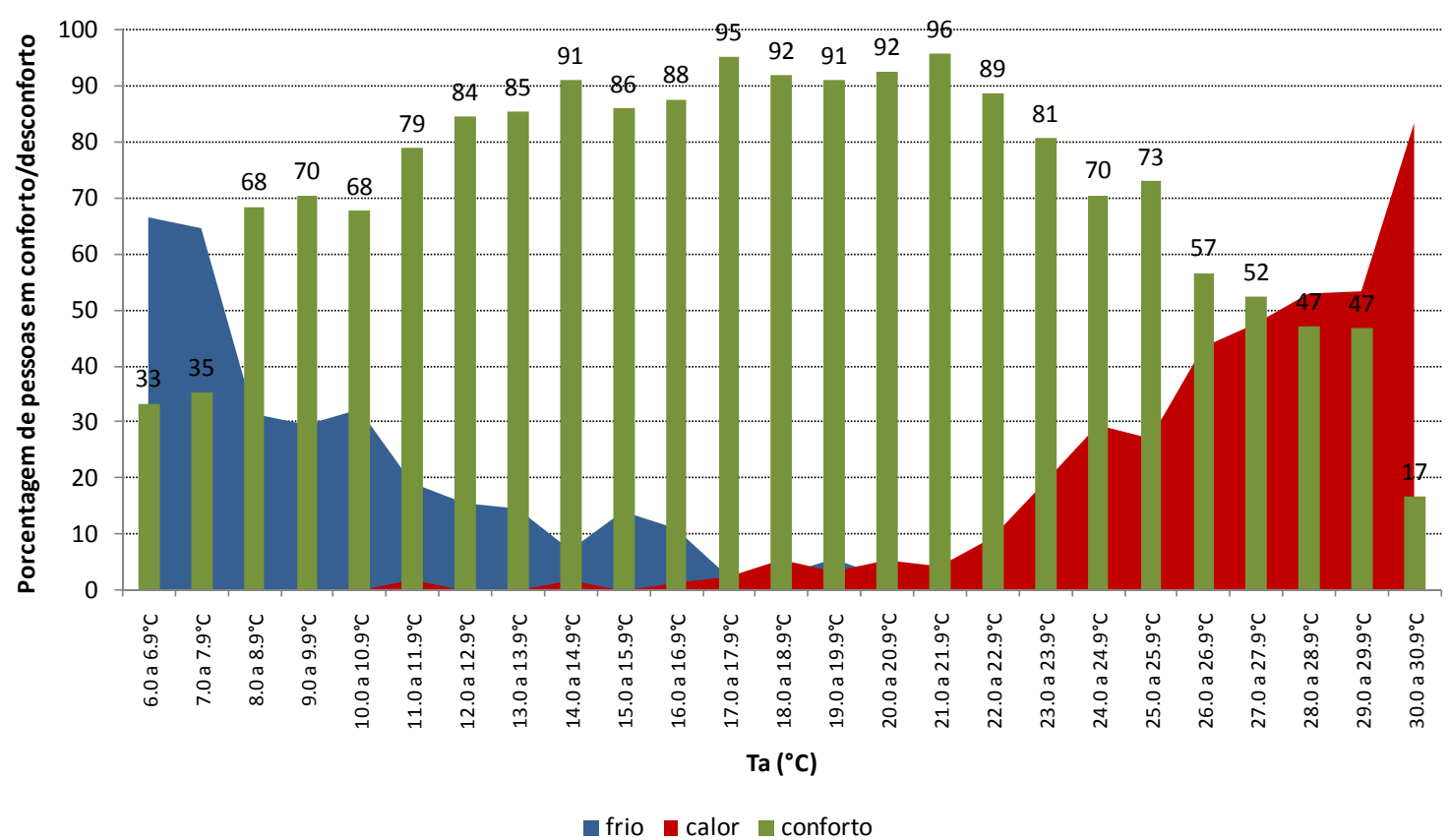

Figura 10 - Percentuais em conforto/desconforto versus Ta

Nota: colunas representam percentuais de pessoas em conforto e as áreas cheias representam, à direita, percentuais de pessoas em desconforto por calor e, à esquerda, percentuais de pessoas em desconforto por frio, para variações de temperatura do ar

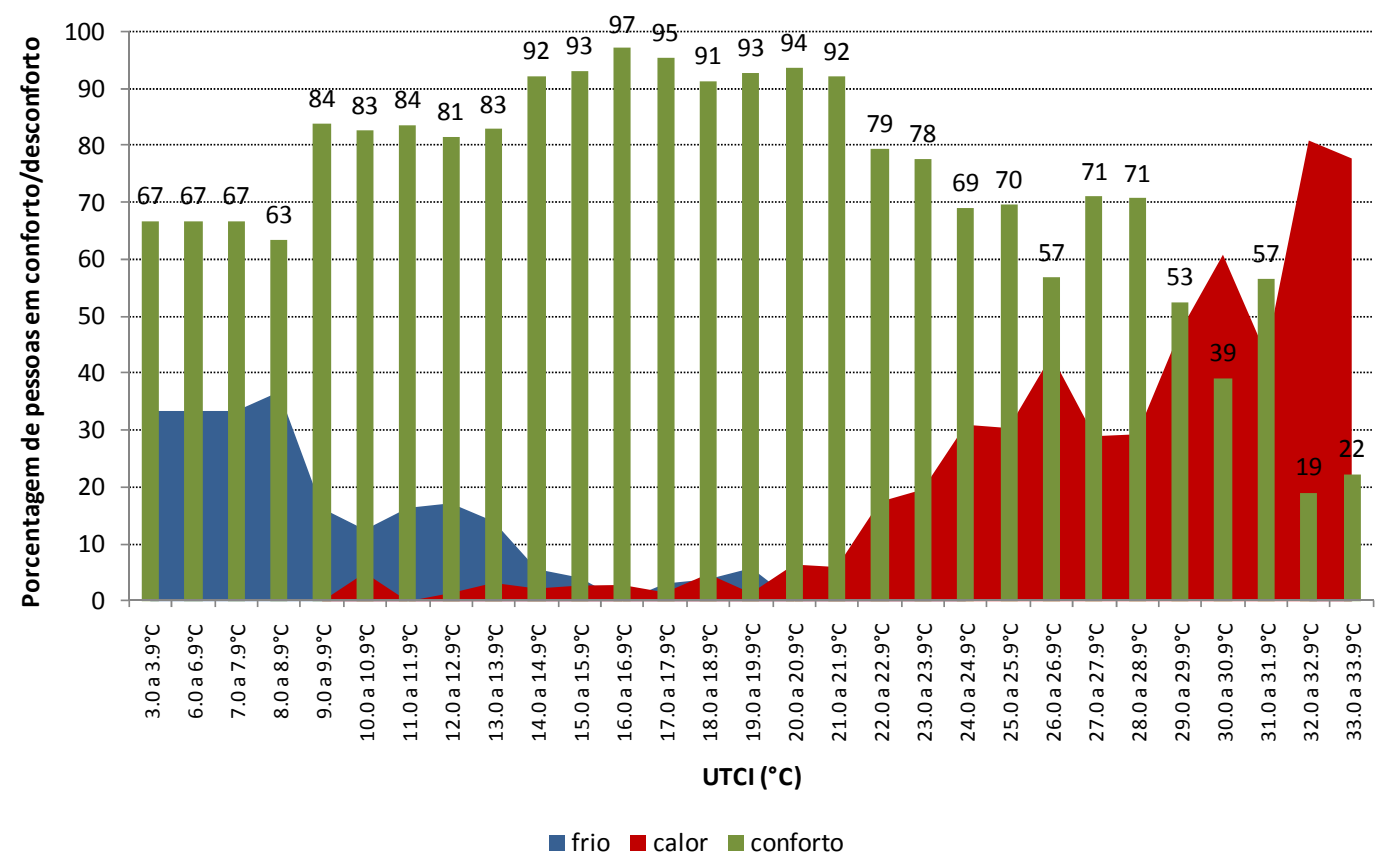

\section{Figura 11 - Percentuais em conforto/desconforto versus UTCI}

Nota: colunas representam percentuais de pessoas em conforto e as áreas cheias representam, à direita, percentuais de pessoas em desconforto por calor e, à esquerda, percentuais de pessoas em desconforto por frio, para variações de temperatura UTCI

Para ambientes internos, aceita-se a margem de $10 \%$ de insatisfeitos em condições de conforto (ISO 7730 (INTERNATIONAL..., 2005)). Para ambientes externos, nos quais as condições climáticas são mais difíceis de controlar, somente as variáveis climáticas não são suficientes para explicar a percepção térmica, pois elas respondem por $50 \%$ da avaliação subjetiva de conforto (NIKOLOPOULOU; STEEMERS, 2003), sugerindo que a tolerância às condições climáticas 
em ambientes abertos é maior. Dessa forma, é necessário definir a margem aceitável de pessoas em desconforto em ambientes abertos. Para o caso de Curitiba, a faixa de temperatura do ar para que mais de $90 \%$ das pessoas estejam em conforto parece ser muito estreita $\left(17-22{ }^{\circ} \mathrm{C}\right.$ Ta), não condizendo com a faixa de temperatura entre $13{ }^{\circ} \mathrm{C}$ e $23{ }^{\circ} \mathrm{C}$ Ta obtida a partir dos votos de conforto (Tabela 6).

A partir do agrupamento dos votos de sensação térmica para cada grau de variação de temperatura do ar e UTCI, e, uma vez que a escala de sete pontos $\mathrm{e}$ as categorias adotadas tanto nos questionários quanto no índice PMV, para o qual foi desenvolvido o índice PPD, são equivalentes, foi calculado o valor do PPD segundo a equação contida na ISO 7730 (INTERNATIONAL..., 2005) (Eq. 3, Tabela 3). A Figura 12 apresenta a relação entre os votos médios de sensação térmica e a porcentagem estimada de insatisfeitos (PPD) para ambas as variáveis. Percebe-se que 0 comportamento dos votos de sensação térmica agrupados é similar aos votos preditos e que a linha de tendência polinomial segue o padrão esperado para ambos os casos (Ta e UTCI).

Nos dois casos, para neutralidade térmica (sensação térmica $=0$ ), há $10 \%$ de pessoas insatisfeitas, ou seja, há um incremento de 5\% em relação ao mínimo estabelecido pela equação original. Ao definir a faixa de $-0,5$ e $+0,5$ como o intervalo de conforto, seguindo o procedimento adotado pela norma ISO 7730 (INTERNATIONAL..., 2005) (categoria B), assumem-se como faixas de conforto para ambas as variáveis os valores indicados na tabela seguinte. A Tabela 7 apresenta também o valor estimado do PPD e temperatura operativa para sensação térmica $=0 . \mathrm{Na}$ coluna mais à direita é sugerido complementarmente um ajuste da equação do PPD (Eq. 1), a partir da melhor aproximação empírica à equação de regressão (curva de tendência). Em ambos os casos, r2 > 0,98 em relação à equação de regressão original (curva de tendência).

Dessa forma, pode-se sugerir a correção da Tabela 1 para as categorias conforto e desconforto, por frio e calor, conforme a Tabela 8 . As duas colunas mais à direita mostram o ajuste do intervalo de conforto às categorias originais do UTCI, e o gráfico da Figura 13 mostra as alterações propostas para as categorias de UTCI, verificando-se a ampliação da faixa de conforto, com a redução proporcional das zonas de leve estresse térmico.

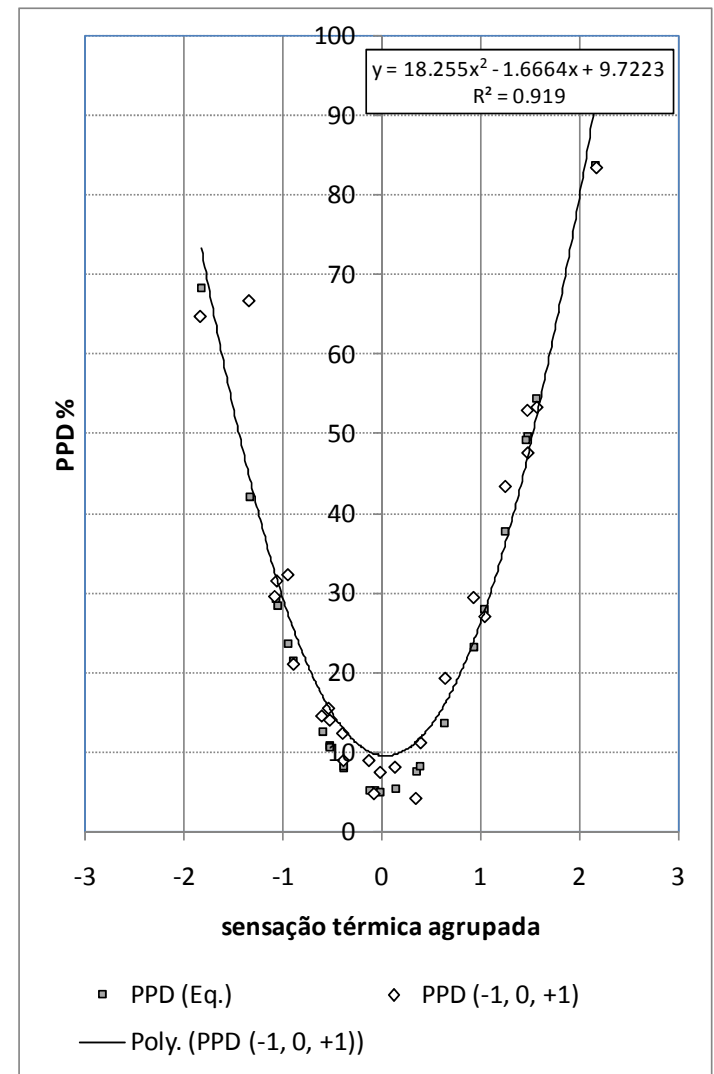

(a)

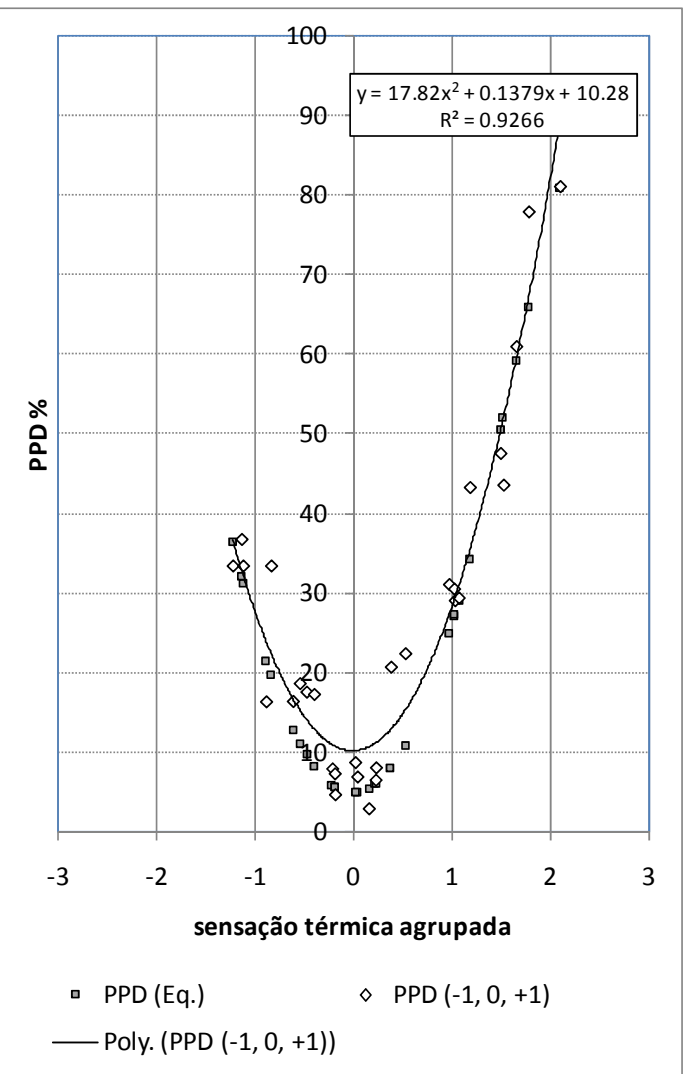

(b)

Figura 12 - Relação entre sensação térmica e PPD: (a) para Ta, (b) para UTCI 
Tabela 7 - Faixas de conforto e desconforto para Ta e UTCI

\begin{tabular}{|c|c|c|c|c|c|c|}
\hline & \multirow{2}{*}{$\begin{array}{c}\text { Frio } \\
{ }^{\circ} \mathrm{C}\end{array}$} & \multirow{2}{*}{$\frac{\text { Conforto }}{{ }^{\circ} \mathrm{C}}$} & \multirow{2}{*}{$\begin{array}{c}\text { Calor } \\
{ }^{\circ} \mathrm{C}\end{array}$} & \multicolumn{2}{|c|}{ Conforto } & \multirow{2}{*}{$\begin{array}{l}\text { Equação ajustada do PPD } \\
\text { (Equação 4)* }\end{array}$} \\
\hline & & & & PPD* & Top & \\
\hline Та & $<15$ & 15 a 24 & $>24$ & $16 \%$ & $\approx 19^{\circ} \mathrm{C} \mathrm{Ta}$ & \multirow{2}{*}{$\begin{array}{l}\mathrm{PPD}=100-90 * \exp (-0,03353 * \mathrm{PMV} 4 \\
-0,2179 * \mathrm{PMV} 2)\end{array}$} \\
\hline UTCI & $<15$ & 15 a 27 & $>27$ & $15 \%$ & $\approx 21^{\circ} \mathrm{C}$ UTCI & \\
\hline
\end{tabular}

Nota: *calculado a partir da equação de regressão da Figura 12.

Tabela 8 - Faixas de conforto/desconforto térmico do UTCI adaptadas às condições de Curitiba

\begin{tabular}{|c|c|c|c|c|}
\hline $\begin{array}{c}\text { Faixas de } \\
\text { UTCI }\end{array}$ & \begin{tabular}{|c|}
$\begin{array}{c}\text { Categorias de } \\
\text { estresse }\end{array}$ \\
\end{tabular} & $\begin{array}{c}\text { Faixas de UTCI } \\
\text { ajustado }\end{array}$ & $\begin{array}{c}\text { Classificação por } \\
\text { conforto/desconforto }\end{array}$ & $\begin{array}{c}\text { Faixas de } \\
\text { UTCI }\end{array}$ \\
\hline$>46^{\circ} \mathrm{C}$ & $\begin{array}{l}\text { extremo estresse } \\
\text { para o calor }\end{array}$ & $>46{ }^{\circ} \mathrm{C}$ & & \\
\hline $38^{\circ} \mathrm{C}$ a $46^{\circ} \mathrm{C}$ & $\begin{array}{l}\text { muito forte estresse } \\
\text { para o calor }\end{array}$ & $38^{\circ} \mathrm{C} \mathrm{a} 46^{\circ} \mathrm{C}$ & & \\
\hline $32{ }^{\circ} \mathrm{C}$ a $38^{\circ} \mathrm{C}$ & $\begin{array}{l}\text { forte estresse para o } \\
\text { calor }\end{array}$ & $32^{\circ} \mathrm{C}$ a $38^{\circ} \mathrm{C}$ & & \\
\hline $26{ }^{\circ} \mathrm{C}$ a $32{ }^{\circ} \mathrm{C}$ & $\begin{array}{l}\text { moderado estresse } \\
\text { para o calor }\end{array}$ & $27^{\circ} \mathrm{C}$ a $32^{\circ} \mathrm{C}$ & $>27^{\circ} \mathrm{C}$ & $\begin{array}{l}\text { Desconforto } \\
\text { por calor }\end{array}$ \\
\hline $18^{\circ} \mathrm{C}$ a $26^{\circ} \mathrm{C}$ & conforto térmico & $15^{\circ} \mathrm{C}$ a $27^{\circ} \mathrm{C}$ & $15^{\circ} \mathrm{C}$ a $27^{\circ} \mathrm{C}$ & Conforto \\
\hline $9^{\circ} \mathrm{C}$ a $18^{\circ} \mathrm{C}$ & $\begin{array}{l}\text { sem estresse } \\
\text { térmico }\end{array}$ & $9^{\circ} \mathrm{C}$ a $15^{\circ} \mathrm{C}$ & $<15^{\circ} \mathrm{C}$ & $\begin{array}{l}\text { Desconforto } \\
\text { por frio }\end{array}$ \\
\hline $0{ }^{\circ} \mathrm{C}$ a $9^{\circ} \mathrm{C}$ & $\begin{array}{l}\text { pouco estresse para } \\
\text { o frio }\end{array}$ & $0{ }^{\circ} \mathrm{C}$ a $9^{\circ} \mathrm{C}$ & & \\
\hline $0{ }^{\circ} \mathrm{Ca}-13^{\circ} \mathrm{C}$ & $\begin{array}{l}\text { moderado estresse } \\
\text { para o frio }\end{array}$ & $0{ }^{\circ} \mathrm{Ca}-13{ }^{\circ} \mathrm{C}$ & & \\
\hline$-13{ }^{\circ} \mathrm{C}$ a $-27^{\circ} \mathrm{C}$ & $\begin{array}{l}\text { forte estresse para o } \\
\text { frio }\end{array}$ & $-13{ }^{\circ} \mathrm{C}$ a $-27^{\circ} \mathrm{C}$ & & \\
\hline$-27^{\circ} \mathrm{C}$ a $-40{ }^{\circ} \mathrm{C}$ & $\begin{array}{l}\text { muito forte estresse } \\
\text { para o frio }\end{array}$ & $-27^{\circ} \mathrm{C} \mathrm{a}-40^{\circ} \mathrm{C}$ & & \\
\hline$<-40{ }^{\circ} \mathrm{C}$ & $\begin{array}{l}\text { extremo estresse } \\
\text { para o frio }\end{array}$ & $<-40{ }^{\circ} \mathrm{C}$ & & \\
\hline
\end{tabular}

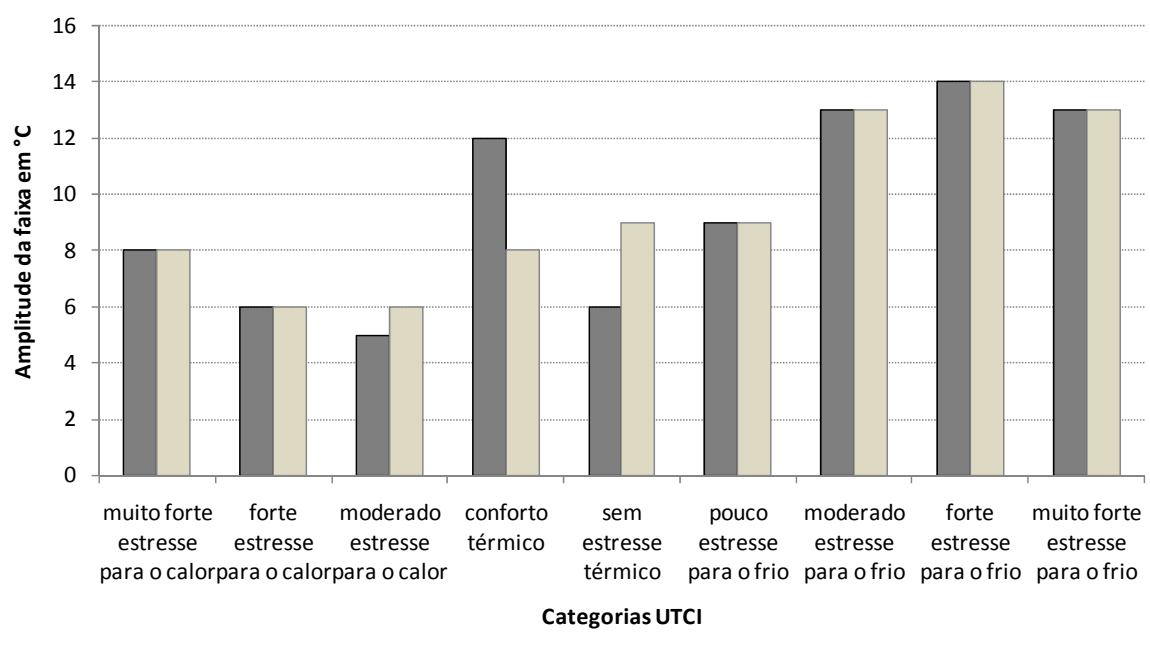

$\square$ UTCl ajustado $\square$ UTCI

Figura 13 - Faixas de UTCI - originais e aj ustadas, expressas em termos de amplitude de cada faixa em graus UTCI 


\section{Conclusões}

A partir dos dados monitorados nas campanhas de campo em Curitiba, no período de janeiro a agosto de 2009, foi possível comprovar a eficácia do índice UTCI na predição de graus de conforto/desconforto térmico. $\mathrm{O}$ menor valor quadrático médio dos erros (RMSE) observado em todos os subgrupos foi inferior a uma unidade na escala de sensação térmica de sete pontos, sugerindo uma razoável capacidade preditiva em todos os subgrupos com razoável grau de ajuste da curva e a não necessidade de calibração do índice UTCI para regiões subtropicais. A partir das análises das respostas de sensação térmica foi possível identificar as seguintes faixas de conforto e desconforto térmico, para a margem de $20 \%$ de insatisfeitos:

(a) desconforto para o frio, $\mathrm{Ta} \leq 15^{\circ} \mathrm{C}$;

(b) conforto, $15{ }^{\circ} \mathrm{C}<\mathrm{Ta}<24{ }^{\circ} \mathrm{C}$; e

(c) desconforto para o calor, $\mathrm{Ta} \geq 24{ }^{\circ} \mathrm{C}$.

A definição da faixa de conforto, considerando as respostas de sensação térmica, partiu da equivalência dos votos $-1,0$ e +1 à situação de conforto. A análise das porcentagens de pessoas em conforto/desconforto mostrou semelhanças, tanto para Ta como para UTCI, com resultados da equação preditiva do PPD, permitindo uma definição preliminar de faixas de conforto para ambas as variáveis.

\section{Referências bibliográficas}

ALI-TOUDERT, F.; MAYER, H. Effects of Street Design on Outdoor Thermal Comfort. In: KISS, A.; MEZÖSI, G.; SÜMEGHY, Z. (Eds.). Landscape, Environment and Society: studies in honour of professor Ilona Bárány-Kevei on the occasion of Her Birthday. p. 45-55, 2006. (SZTE Éghajlattani és Tájföldrajzi Tanszék, Természeti Földrajzi és Geoinformatikai Tanszék, Szeged.)

AMERICAN SOCIETY OF HEATING, REFRIGERATING AND AIR CONDITIONING ENGINEERS. Standard 55: thermal environmental conditions for human occupancy. Atlanta, 2004.

BRÖDE, P.; FIALA, D.; BLAZEJCZYK, K. Deriving the Operational Procedure for the Universal Thermal Climate Index UTCI. International Journal of Biometeorology, special issue UTCI, 2011.
BRÖDE, P. et al. Deriving the Operational Procedure for the Universal Thermal Climate Index UTCI. International Journal of Biometeorology, special issue UTCI, 2011.

BRÖDE, P.; KRÜGER, E.; ROSSI F. Assessment of Urban Outdoor Thermal Comfort by the Universal Thermal Climate Index UTCI. In: KOUNALAKIS, S.; KOSKOLOU, M. (Eds.). INTERNATIONAL CONFERENCE ON ENVIRONMENTAL ERGONOMICS, 14., Nafplio, Greece, 2011. Proceedings... Athens: National and Kapodestrian University of Athens, 2011.

CAMPBELL, S. Application Note: weather station sitting and installation tools. [s.1]: 1997.

CHRISOMALLIDOU, N.; CHRISOMALLIDIS, M.; THEODOSIOU, T. Design Principles and Applications. In: NIKOLOPOULOU, M. (Eds.).

Designing Open Spaces in the Urban

Environment: a bioclimatic approach. Greece: CRES, 2004.

DANNI-OLIVEIRA, I. M. Aspectos Climáticos Curitiba, PR. Ra'ega, Curitiba, v. 3, p. 229-253, 1999.

DE DEAR, R. J.; FOUNTAIN, M. E. Field Experiments on Occupant Comfort and Office Thermal Environments in a Hot-Humid Climate. ASHRAE Transactions, v. 100, n. 2, p. 457-474, 1994.

ELIASSON, I. et al. Climate and Behaviour in a Nordic City. Landscape and Urban Planning, v. 82, n. 1/2, p. 72-84, 2007.

FANGER, P. O. Thermal Comfort. Florida: Robert E. Krieger Publishing Co., 1982.

FIALA, D.; LOMAS, K. J.; STOHRER, M. A Computer Model of Human Thermoregulation for a Wide Range of Environmental Conditions: the passive system. Journal of Applied Physiology, v. 87, p. 1957-1972, 1999.

FIALA, D.; LOMAS, K. J.; STOHRER, M. Computer Prediction of Human Thermoregulatory and Temperature Responses to a Wide Range of Environmental Conditions. International Journal of Biometeorology, v. 45, n. 3, p. 143-159, 2001.

FIALA, D.; LOMAS, K. J.; STOHRER, M. First Principles Modeling of Thermal Sensation Responses in Steady-State and Transient Conditions. ASHRAE Transactions, v. 109, p. 179-186, 2003. 
FIALA, D.; LOMAS, K. J.; STOHRER, M. Dynamic Simulation of Human Heat Transfer and Thermal Comfort. In: MEKJAVIC, I. B.; KOUNALAKIS, S. N.; TAYLOR, N. A. S. (Eds.). In: INTERNATIONAL CONFERENCE ON ENVIRONMENTAL ERGONOMICS, 12., Portoroz, Slovenia, 2007. Proceedings... Portoroz, Slovenia, 2007. p. 513-515.

FIALA, D. et al. UTCI-Fiala Multi-Node Model of Human Heat Transfer and Temperature Regulation. International Journal of Biometeorology, special issue UTCI, 2011.

GIVONI, B. Climate Considerations in Building and Urban Design. Nova Iorque: ITP, 1998.

HÖPPE, P. Different Aspects of Assessing Indoor and Outdoor Thermal comfort. Energy and Building, v. 34, n. 6, p. 661-665, jul. 2002.

INTERNATIONAL ORGANIZATION FOR STANDARDIZATION. ISO 7726: ergonomics of the thermal environments: instruments for measuring physical quantities. Genève, 1998.

INTERNATIONAL ORGANIZATION FOR STANDARDIZATION. ISO 7730: ergonomics of the thermal environments: analytical determination and interpretation of thermal comfort using calculation of the PMV and PPD indices and local thermal comfort criteria. Genève, 2005.

INTERNATIONAL ORGANIZATION FOR STANDARDIZATION. ISO 10551: ergonomics of the thermal environments: assessment of the influence of the thermal environment using subjective judgment scales. Genève, 1995.

INTERNATIONAL ORGANIZATION FOR STANDARDIZATION. ISO 9920: ergonomics of the thermal environment: estimation of thermal insulation and water vapour resistance of a clothing ensemble. Genève, 2007.

INTERNATIONAL SOCIETY OF BIOMETEOROLOGY. Commission 6 for the Development of a Universal Thermal Climate Index (UTCI). Meeting Report, Freiburg, Germany, june 7-8, 2001. Freiburg: ISB Commission, 2001.

INTERNATIONAL SOCIETY OF BIOMETEOROLOGY. Commission 6 for the Development of a Universal Thermal Climate Index (UTCI). Report for 2003. Genebra: ISB Commission 6, 2003.

JOHANSSON, E. Influence of Urban Geometry on Outdoor Thermal Comfort in a Hot Dry Climate: a study in Fez, Morocco. Building and Environment, v. 41, p. 1326-1338, 2006.
JOHANSSON, E.; EMMANUEL, R. The Influence of Urban Design on Outdoor Thermal Comfort in the Hot, Humid City of Colombo, Sri Lanka. International Journal of Biometeorology, v. 51, p. 119-133, out. 2006.

KATZSCHNER, L. The Contribution of Urban Climate Studies to a New Urbanity. In: ENCONTRO NACIONAL DE CONFORTO NO AMBIENTE CONSTRUÍDO, 8., Maceió, 2005. Anais... Maceió: ANTAC, 2005.

KATZSCHNER, L.; MÜLDER, J. Regional Climatic Mapping as a Tool for Sustainable Development. Journal of Environmental Management, v. 87, p. 262-267, 2005.

KNEZ, I. et al. Psychological Mechanisms in Outdoor Place and Weather Assessment: towards a conceptual model. International Journal of Biometeorology, v. 53, p. 101-111, 2009.

KNEZ, I.; THORSSON, S. Influence of Culture and Environmental attitude on Thermal, Emotional and Perceptual Evaluations of a Public Square. International Journal of Biometeorology, v. 50, n. 5 , p. 258-268, 2006.

KRÜGER, E. L.; MINELLA, F. O.; RASIA, F. Impact of Urban Geometry on Outdoor Thermal Comfort and Air Quality from Field Measurements in Curitiba, Brazil. Building and Environment, v. 46, n. 3, p. 621-634, 2011.

KUCZMARSKI, R. J. et al. 2000 CDC Growth Charts for the United States: methods and development. Vital and Health Statistics, v. 11, n. 246, p. 1-190, 2002.

MENDONÇA, F. Clima e Criminalidade. Curitiba: Ed. da UFPR, 2001.

MONTEIRO, L. M.; ALUCCI, M. P. Comparação Cruzada Entre Pesquisas Laboratoriais e de Campo em Conforto Térmico em Espaços Abertos Urbanos. Ambiente Construído, Porto Alegre, v. 10, n. 4, p. 79-101, out./dez. 2010.

NIKOLOPOULOU, M.; BAKER, N.; STEEMERS, K. Thermal Comfort in Outdoor Urban Spaces: understanding the human parameter. Solar Energy, v. 70, n. 3, p. 227-235, 2001.

NIKOLOPOULOU, M.; STEEMERS, K. Thermal Comfort and Psychological Adaptation as a Guide for Designing Urban Spaces. Energy and Building, v. 35, n. 1, p. 95-101, 2003.

NIKOLOPOULOU, M. Outdoor Comfort. In: STEEMERS, K.; STEANE, M. A. (Eds.). Environmental Diversity in Architecture. Oxford: Spon Press, 2004. chapter 7, p,101-119. 
NIKOLOPOULOU, M.; LYKOUDIS, S. Thermal Comfort in Outdoor Urban Spaces: analysis across different European countries. Building and Environment, v. 41, n. 11, p. 1455-1470, nov. 2006.

PANOGOPOULOS, T. Using Microclimatic Landscape Design to Create Thermal Comfort and Energy Efficiency, In: CONFERÊNCIA SOBRE EDIFÍCIOS EFICIENTES, 1., Algarve, 2008. Actas... Algarve, 2008.

PEREIRA, I. M.; ASSIS, E. S. Avaliação de Modelos de Índices Adaptativos Para Uso no Projeto Arquitetônico Bioclimático. Ambiente Construído, Porto Alegre, v. 10, n. 1, p. 31-51, jan./mar. 2010.

PICOT, X. Thermal Comfort in Urban Spaces: impact of vegetation growth case study, Piazza della Scienza, Milan, Italy. Energy and Buildings, v. 36, n. 4, p. 329-334, 2004.

SHASHUA-BAR, L.; HOFFMAN, M. E. Vegetation as a Climatic Component in the Design of an Urban Street: an empirical model for predicting the cooling effect of urban green areas with trees. Energy and Buildings, v. 31, n. 3, p. 221-235, abr. 2000.

SOUZA, L. C. L. et al. Fator de Visão do Céu e Intensidade de Ilhas de Calor na Escala do Pedestre. Ambiente Construído, Porto Alegre, v. 10, n. 4, p. 155-167, out./dez. 2010.
SPAGNOLO, J.; DE DEAR, R. A Field Study of Thermal Comfort in Outdoor and Semi-Outdoor Environments in Subtropical Sydney, Australia. Building and Environment, v. 38, n. 5, p. 721738, maio 2003.

THORSSON, S. et al. Different Methods for Estimating the Mean Radiant Temperature in an Outdoor Urban Setting. International Journal of Biometeorology, v. 27, n. 14, p. 1983-1993, 2007.

THORSSON, S.; LINDQVIST, M.; LINDQVIST, $\mathrm{S}$. Thermal Bioclimatic Conditions and Patterns of Behaviour in an Urban Park in Göteborg, Sweden. International Journal of Biometeorology, v. 48, n. 3, p. 149-156, 2004.

\section{WORLD HEALTH ORGANIZATION. Physical}

Status: the use and interpretation of anthropometry. WHO Technical Report Series No. 854, 2005. World Health Organization, Geneva. Disponível em:

$<$ http://whqlibdoc.who.int/trs/WHO_TRS_854.pdf >. Acesso em: 2 ago. 2010.

WORLD HEALTH ORGANIZATION. Expert Consultation. Appropriate Body-Mass Index for Asian Populations and Its Implications for Policy and Intervention Strategies. Lancet., v.. 363, n. 9403, p. 157-163, 2004.

\section{Agradecimentos}

Ao CNPq e à Capes, pelo apoio financeiro sob a forma de Projeto Universal, concessão de bolsas de mestrado, doutorado e de doutorado-sanduíche.

Revista Ambiente Construído

Associação Nacional de Tecnologia do Ambiente Construído

Av. Osvaldo Aranha, 99 - 30 andar, Centro

Porto Alegre - RS - Brasil

CEP 90035-190

Telefone: +55 (51) 3308-4084

Fax: +55 (51) 3308-4054

www. seer. ufrgs. br/ ambienteconstruido

E-mail: ambienteconstruido@ufrgs.br 